\title{
Development of Cold-Bonded Briquettes Using By-Product-Based Ettringite Binder from Ladle Slag
}

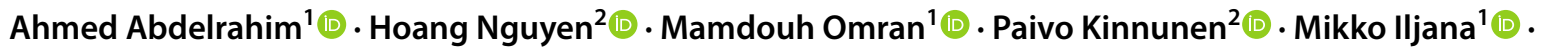 \\ Mirja Illikainen $^{2} \cdot$ Timo Fabritius $^{1}$
}

Received: 2 July 2021 / Accepted: 4 February 2022 / Published online: 18 February 2022

(c) The Author(s) 2022

\begin{abstract}
The recycling of steel plant side streams through cold-bonded briquettes has become quite common. However, Portland cement is mainly used as a binder in the briquettes, contributing significantly to the energy consumption, costs, and carbon footprint associated with the production of cold-bonded briquettes. This paper reports on a more sustainable method for side stream recycling that involves replacing cement with an ettringite-based binder. Ettringite binders develop early high strength and mainly consist of ladle slag, another side stream of the industry. Here, the ettringite-based binder is assessed in terms of its mechanical and thermal properties against a reference briquette made using the conventional technique. Three different briquette types are produced using several side stream materials and varying ettringite-based binder content. Briquettes produced using $15 \%$ and higher ettringite-based binder content exhibited excellent mechanical properties within a shorter curing period compared to conventional used binder. Moreover, the ettringite-based binder briquettes exhibited a better swelling behavior to conventional cement briquettes under conditions simulating a blast furnace.
\end{abstract}

The contributing editor for this article was Adam Clayton

Powell.

Ahmed Abdelrahim

ahmed.abdelmonem@oulu.fi

Hoang Nguyen

hoang.nguyen@oulu.fi

Mamdouh Omran

mamdouh.omran@oulu.fi

Paivo Kinnunen

paivo.kinnunen@oulu.fi

Mikko Iljana

mikko.iljana@oulu.fi

Mirja Illikainen

mirja.illikainen@oulu.fi

Timo Fabritius

timo.fabritius@oulu.fi

1 Process Metallurgy Research Unit, University of Oulu, Pentti Kaiteran Katu 1, 90014 Oulu, Finland

2 Fibre and Particle Engineering Research Unit, University of Oulu, Pentti Kaiteran Katu 1, 90014 Oulu, Finland 


\section{Graphical Abstract}

\section{Performance of briquettes utilizing 10, 15 and 20\% Ettringite based binder Vs. Portland cement and GGBFS as a binder}

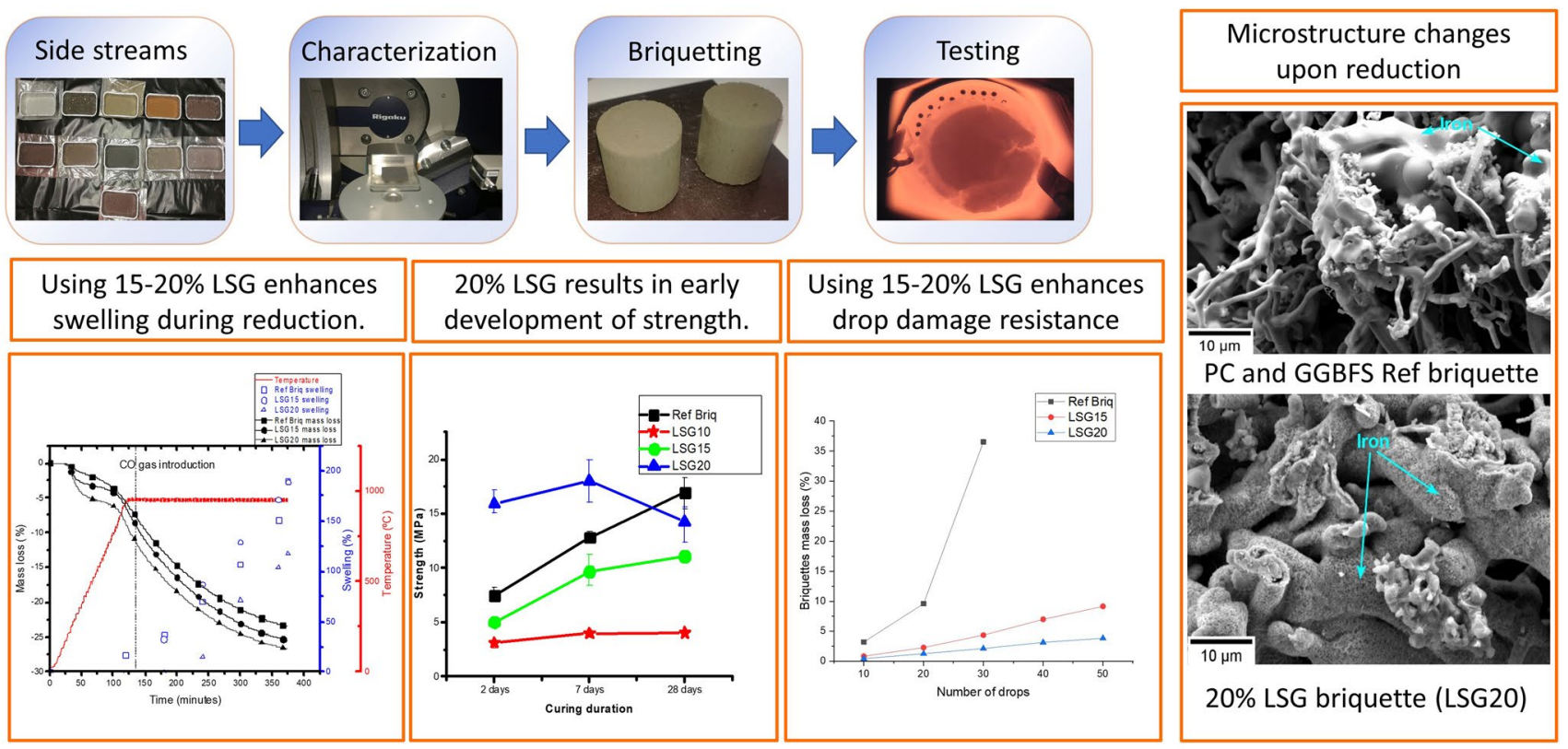

Keywords Briquettes $\cdot$ Blast furnace $\cdot$ Swelling $\cdot$ Ettringite-based binder

\section{Introduction}

During steel production, several side streams are generated. Conventionally, such side streams are landfilled or recycled through sintering plants; however, many of these side streams are rich in iron and carbon, which make them suitable for recycling into different steelmaking processes, such as the blast furnace, electric arc furnace, and basic oxygen furnace. Therefore, due to growing environmental restrictions, as well as the shutdown of several sintering plants, especially in Europe and North America [1], several beneficiation techniques have been innovated to allow for better utilization of such streams in order to reintroduce them to the ironmaking process. These methods range from agglomeration techniques (such as pelletizing and briquetting) to hydrometallurgical, thermal, and physical techniques [2].

Cold-bonded agglomeration has emerged as an alternative to the sintering process as one of the more common beneficiation techniques [3]. A briquette is an agglomerate produced and shaped by pressure while utilizing a binder usually under ambient temperatures [4]. The briquetting process has several benefits including energy savings and reducing environmental load and costs resulting from landfilling $[2,5,6]$. Briquettes must maintain certain chemical and mechanical properties to be suitable for recycling in different steelmaking processes [7]. Moreover, the binders used in briquettes must meet certain physical and chemical properties to ensure the success of the briquetting process [8]. The use of briquettes in blast furnaces (BFs) leads to increased contact between the carbonaceous material and ore bed, which ultimately results in improved $\mathrm{CO}$ gas utilization and a lowered temperature of the thermal reserve zone [9].

Several plants in Sweden, Finland, and the USA have successfully adopted cement-bonded briquetting with the aim of recycling side streams [10-12]. Although the raw materials for ordinary Portland cement (OPC) have a relatively low cost, their production is energy-intensive and associated with high carbon dioxide emissions (up to $913 \mathrm{~kg} \mathrm{CO}_{2}$ /t) [13]. Following their production, briquettes may require curing for $24 \mathrm{~h}$ under high humidity conditions at a temperature of around $20^{\circ} \mathrm{C}$ [14]. Moreover, disadvantages involved in the use of cement-bonded briquettes also include briquette disintegration at low temperatures, increased temperature imbalance in the furnace, and higher energy requirements associated with additional slag formation [15]. The use of briquettes with low strength in BFs, for example, may result in fine generation, which would lower the permeability in the furnace shaft, leading to lower furnace efficiency [6].

Many attempts - with varying degrees of successhave been made to replace the cement in cold-bonded 
briquettes with different organic and inorganic binders. Binder limitations stem from the presence of impurities, high production costs, and insufficient green strength [7, 16-19]. For example, using bentonite as a binder results in contamination of product with silica, which may ultimately lead to an increase in energy consumption during production [7]. The use of plastics as a binder is challenging due to the fact that dissociation temperature of plastics is lower than that of iron oxide reduction [16]. Lime and finely dispersed slag may not ensure the required green strength of briquettes when used as binders [19]. Petroleum-based binders used in briquetting may result in the release of volatile substances upon charging [19]. This study is focused on producing cement-free briquettes using ettringite-based binders from ladle slag. Ladle slags are produced either through BOF or EAF steelmaking routes, and they usually contain less than $3 \% \mathrm{FeO}$. However, in certain melt shops, this content may rise up to $10 \%$ [5]. Ladle slag may be crushed and recycled back to the ladle in order to assist in the formation of the same slags [5]. Ladle slag has a $\mathrm{CaO} / \mathrm{SiO}_{2}$ ratio of around 2 and contains calcium aluminates and calcium silicate as its main mineral phases $[20,21]$. It also has a relatively high $\mathrm{Al}_{2} \mathrm{O}_{3}$ content compared to other steel slags. However, basicity and $\mathrm{Al}_{2} \mathrm{O}_{3}$ content may considerably vary depending on the refining process in ladle slag with some sources reporting $\mathrm{CaO} / \mathrm{SiO}_{2}$ ratio up to 8 and $\mathrm{Al}_{2} \mathrm{O}_{3}$ content as low as $1.3 \%$ [22-26]. Calcium aluminates and calcium silicate are both favorable for use in binders, with the former exhibiting a very fast reaction time and the latter increasing the molar ratio of calcium, resulting in enhanced hydraulic properties [20]. Moreover, slowly cooled ladle slag has a very high content of fine powder due to the conversion of $\beta-\mathrm{C}_{2} \mathrm{~S}$ to $\gamma-\mathrm{C}_{2} \mathrm{~S}$ [21]. Previous researchers have suggested the use of ladle slag alone or in combination with granulated ground blast furnace slag (GGBFS) in briquettes made for recycling purposes [22, 27]. However, GGBFS is a product that can be used to replace ordinary Portland cement (OPC), and therefore replacing it with lower-value side streams would incur further benefits.

Here, in this study, the thermal and mechanical properties of the produced briquettes using ettringite-based binder are compared against conventional briquettes produced using rapid Portland cement and GGBFS cement. The aim is to produce briquettes with enhanced characteristics to minimize fine particle generation and sustain adequate levels of furnace permeability during furnace operation. The study also aims to increase the use of inplant fines by attempting to minimize the binder share in the briquette and to analyze the mechanical and thermal behavior of briquettes produced using ettringite-based binders.

\section{Materials and Methods}

\section{Materials}

\section{Side Streams}

Several side stream materials used in this work were obtained from the SSAB plant in Raahe, Finland. These materials were evaluated for their physical and chemical properties. Representative samples were taken using a standard conning and quartering method [28]. Samples were dried, and their moisture content was determined by the heating samples in a lab oven at $105{ }^{\circ} \mathrm{C}$ until a constant mass was achieved. The apparent density of each material was determined based on the average of three measurements according to the ISO standard [29] using the following equation:

Bulk density $=\frac{\text { Sample mass }}{\text { Volume of the sample }}$

A gas pycnometer, AccuPyc II 1340, was used to determine the skeleton density $\left(\rho_{S}\right)$ for each of the side stream materials. True density is defined as the mass of a substance divided by its volume, excluding open and closed pores. The pycnometer uses helium as the displacement gas and had a $10 \mathrm{~cm}^{3}$ sample chamber. Determination of skeletal density does not exclude the closed pores volumes since helium may not be able to penetrate through the closed pores. True density could only be equal to the skeletal density if no internal/closed pores exist in the material. The skeletal density of each material was determined based on the average of three consecutive measurements.

To obtain the particle size distribution (PSD) of each material, an adequate representative sample of each material was sieved using the commercially available Analysette 3 Pro Vibratory Sieve Shaker from Fritsch, Germany to separate the coarser fraction. The PSD of the finer fraction (less than $2 \mathrm{~mm}$ ) was then determined using Beckman Coulter LS 13320 Universal Liquid Module Laser Diffraction Particle Size Analyzer.

A calibrated Panalytical Axios Max wavelength-dispersive spectrometer equipped with a rhodium anode tube was used for the X-ray fluorescence (XRF) analyses. The carbon content of the samples was determined using LECO CS-200 and calibrated against a sample with predetermined carbon and sulfur content (AR 309). The mineralogical composition of the samples was determined using Rigaku SmartLab $9 \mathrm{~kW}$ with a $2 \theta$ angle ranging from 4 to $90^{\circ}$ and a step of $0.02^{\circ}$. The samples were scanned at $40 \mathrm{kV}$ and $135 \mathrm{~mA}$. Phases were identified from the diffraction pattern using PDXL 2.6, Rigaku integrated X-ray powder diffraction software. 


\section{Ettringite-Based Binder from Ladle Slag and Gypsum}

The ettringite-based binder (LSG) was formed from the hydration between the ladle slag (LS-a by-product of the steelmaking process from the ladle furnace) and synthetic gypsum (G). The LS was provided by SSAB Europe Oy (Raahe, Finland), and the commercial gypsum was supplied by VWR Finland (product code: 22,451.360). The former was ground by a ball mill to reach a $\mathrm{d}_{50}$ value of approximately $10 \mu \mathrm{m}$, which is similar to previous work [30], while the latter was used as received, with the $\mathrm{d}_{50}$ being roughly $12 \mu \mathrm{m}$. In addition, citric acid (product code: C1949, supplied by Tokyo Chemical Industry Co., Ltd., Japan) was used as a set retarder to control the workability of the LSG. This acid has been effectively used in ettringite-based binders $[20,31]$ via the reduction in the dissolution rate of calcium in the cement grains [32].

As reported in [30,33], ettringite is the dominant crystalline phase in the structure of LSG and, hence, the strengthgiving phase at an early age for the material. Furthermore, details on the material mineralogy, characterization, and analysis of LSG were well detailed in our previous work [30, 33, 34]. Ettringite was formed in the binder within minutes after exposure to the precursors with water, and the main hydrates were ettringite, monosulfate, amorphous aluminum hydroxide, and a C-(A-)S-H gel. Therefore, LSG exhibits potential to be used as a high early-age strength cementitious binder to produce briquettes.

\section{Binder Preparation and Briquette Making}

Two types of binders were used: The first binder consisted of rapid cement and ground granulated blast furnace slag cement with a ratio of 50:50, while the second binder used was a LSG binder. Briquettes produced using the first binder were used as reference briquettes to assess their performance against the LSG binder. The first type of briquette is referred to as reference briquettes. The reference briquette contained a $12.6 \%$ binder on a dry mass basis, while three LSG briquettes types were produced with a binder content of $10 \%$, $15 \%$, and $20 \%$. Details about the proportion between binder and side streams in reference briquette are covered by industrial confidentiality. All briquettes consisted of a mixture of side stream materials, binder, and water. The mixture of side stream materials in all produced briquettes consisted of components listed in Table 1. Desulfurization scrap is obtained from post-processing of slag from primary and secondary desulfurization process. The post-processing involves magnetic separation of the metallic portion of the slag. Similarly, steel scrap was obtained from post-processing of BOF slag.

To prepare the reference briquettes, side stream materials and binders were dry mixed together using a lab bowl mixer until a homogenous mixture was obtained. Water
Table 1 Side stream material mixtures

\begin{tabular}{lc}
\hline Material & Content $(\%)$ \\
\hline Coarse pellet fines & 7.11 \\
Fine pellet fines & 19.88 \\
Cast house dust & 4.01 \\
Coke dust & 4.94 \\
Premix (60:40 steel scrap and BF top dust) & 21.99 \\
Briquette fines & 12.51 \\
Desulfurization scrap & 5.56 \\
Mill scale & 21.37 \\
Steel scrap & 2.63 \\
\hline
\end{tabular}

was added gradually afterward, and mixing continued for another five minutes to produce the wet paste. To produce LSG briquettes, the binder was first prepared by dry mixing gypsum and ladle slag powder. This was followed by adding the required recipe water with dissolved citric acid to the mix. All binder components were thoroughly mixed. The side stream materials were dry mixed separately and were then wet mixed with the binder. The mixing was also continued for another five minutes until a homogenous mixture was achieved.

Briquettes were made using a lab press and die briquetting machine. Moisture content and briquetting force play a crucial role in determining the produced briquette strength $[35,36]$. To optimize the reference briquette properties, four different sets (three briquettes in each set) were produced using a moisture content of $8.5 \%$ and $9.5 \%$ and a briquetting pressure of 100 bar and 200 bar. It was found that briquettes produced using a moisture content of $9.5 \%$ and a briquetting pressure of 100 bar yielded the best compression strength. Therefore, these two factors were kept constant in all produced briquettes. The produced briquettes had a diameter and height of 55.5 and $51.0 \mathrm{~mm}$, respectively. The briquettes produced using rapid cement and GGBFS were labeled "Ref," while those produced using $10 \%, 15 \%$, and $20 \%$ of the new LSG binder were labeled LSG10, LSG15, and LSG20, respectively.

Curing of the reference briquettes took place under high humidity conditions during the first two days and then under ambient conditions until the 28th day. Curing of the LSG briquettes took place for the same durations with the difference that curing was done under ambient laboratory conditions, which may offer a more cost-efficient option compared to high humidity, elevated temperature chambers that are conventionally used for the curing of cement briquettes.

\section{Briquette Particle Packing}

Filling the voids between coarse particles when making briquettes results in a significant strength increase. Some 
researchers have suggested this could be achieved by increasing the finer fraction in briquettes up to $30 \%$, while others have concluded that $80 \%$ of the material feed in briquette production should be finer than $200-250 \mu \mathrm{m}$ in order to obtain optimum strength $[35,37,38]$.

To produce the reference briquette, the particle packing of the briquette was first checked using EMMA (Elkem Materials Mixture Analyzer) software. EMMA software [39] predicts optimum packing, utilizing either an Andreassen model or modified Andreassen model. The software then displays the optimum packing line (target line) against the resultant packing line (recipe line) based on the PSD and density of the recipe mixture components provided by the user. Better recipe packing is achieved with the recipe line approaching the target line. Unlike the Andreassen model, the modified Andreassen model considers a minimum particle size value, which makes it more suitable for practical applications. Moreover, it was found that a $100 \%$ packing density could be obtained using a distribution coefficient of 0.37 or less $[40,41]$. The modified Andreassen equation is as follows:

$\frac{C P F T}{100}=\frac{\left(D^{q}-D_{S}^{q}\right)}{\left(D_{L}^{q}-D_{S}^{q}\right)}$,

where CPFT is the "Cumulative Percent Finer Than," D is the particle size (diameter), $\mathrm{D}_{\mathrm{L}}$ is the maximum particle size, $\mathrm{D}_{\mathrm{S}}$ is the minimum particle size, and $\mathrm{q}$ is the distribution coefficient.

\section{Briquette Testing and Characterization}

\section{Compressive Test}

The compression test was conducted according to BS ISO 4700:2007 utilizing the $100 \mathrm{kN}$ Zwick/Z100 testing machine. Briquettes were compressed at a constant speed of $10 \mathrm{~mm} /$ min between two parallel flat platens. The test was considered completed either when the load fell to less than $50 \%$ of the maximum load recorded or when the gap between the platens became less than $50 \%$ of the initial diameter of the test specimen [42].

\section{Drop Test}

In the drop test, each sample was dropped from a height of $1 \mathrm{~m}$ into a box made of steel, and its mass was recorded after each drop. The procedure was repeated until either the briquette lost $50 \%$ of its original mass or when it survived 50 drops without dropping below $50 \%$ of its original mass. The number of drops was then recorded as an indication of the drop damage resistance. A similar drop test approach was adopted in recent research [17]. Fines generated after each briquette drop were collected, and their mass was determined.

\section{Phase Characterization}

Two sets of briquettes were examined using a Zeiss ULTRA plus field-emission scanning electron microscope (FESEM) attached to an energy-dispersive X-ray spectroscopy (EDS) detector in order to study their structure, morphology, and chemical composition. The briquette pieces of the first set were mounted in epoxy resin using a JEE-420 Vacuum Evaporator to avoid air bubble formation. The surface of the samples was polished afterward using Struers LaboPol-6 with different grinding and polishing discs. The final polishing steps were taken using a $0.25 \mu \mathrm{m}$ abrasive cloth and $\mathrm{EtOH}$ as a lubricant at a force of $10 \mathrm{~N} / \mathrm{specimen}$ and $150 \mathrm{rpm}$ for two minutes. Finally, the specimen was carbon coated.

The briquette pieces from a second set of briquettes were examined without prior polishing. This set was used to study the morphology of the briquettes, and it was not polished in order to avoid information loss regarding smaller particles found on the surface of bigger particles that would otherwise be lost due to polishing [43]. The composition of certain areas of interest was determined using EDS. Moreover, EDS was used to generate element maps of certain polished sections.

Similar to raw product characterization, the mineralogical composition of the samples was determined by X-ray diffraction (XRD) using Rigaku SmartLab $9 \mathrm{~kW}$ in the range $2 \theta$ of 5 to $120^{\circ}$ with a step of $0.02^{\circ}$. The samples were scanned under $40 \mathrm{kV}$ and $135 \mathrm{~mA}$ conditions. Phase analysis of the diffraction pattern was performed using Rigaku integrated X-ray powder diffraction software PDXL 2.6.

\section{TGA-MS Analysis}

TGA-MS measurements were carried out using Netzsch STA 449F3 coupled with Quadrupole Mass Spectrometer (QMS) 403 Aëolos Quadro. Analysis was done using Netzsch Proteus 6.1 software. The sample used was a piece of the briquette weighing around $4 \mathrm{~g}$. Then, the sample was heated from 30 to $1600{ }^{\circ} \mathrm{C}$ in an $\mathrm{Ar}$ atmosphere at a flow rate of $40 \mathrm{ml} / \mathrm{min}$ and a uniform heating rate of $30^{\circ} \mathrm{C} / \mathrm{min}$.

\section{Blast Furnace Simulator High-Temperature Behavior}

To assess the behavior of the produced briquettes under high-temperature resembling conditions in a $\mathrm{BF}$, a modified blast furnace simulator (BFS) was used. The schematic diagram of the BFS, which was used in our previous work to study pellet reduction [44], is shown in Fig. 1.

The BFS consists of a tube furnace with a sample basket connected to a scale to continuously measure the sample 


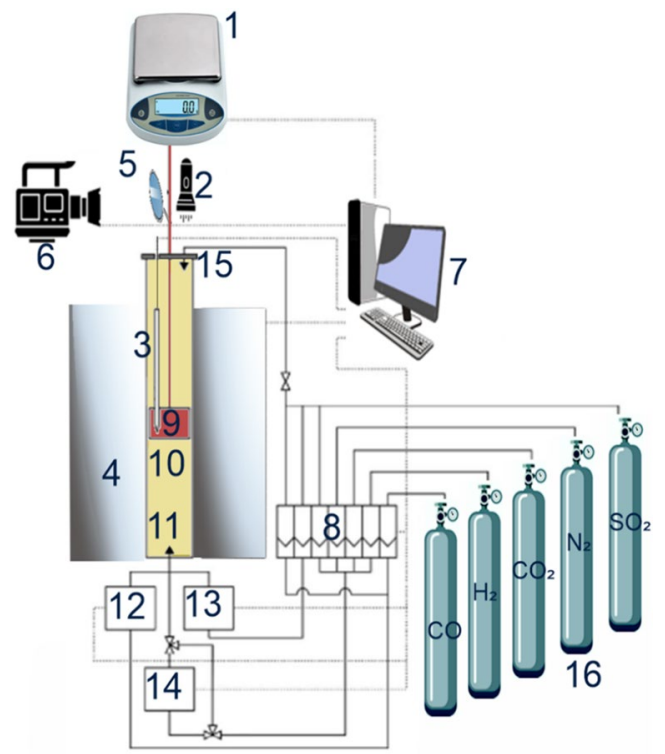

Fig. 1 Schematic diagram of BFS experimental setup with (1) scale, (2) light torch, (3) thermocouple, (4) electrically heated furnace, (5) mirror, (6) video camera, (7) computer system, (8) mass flow control, (9) sample basket, (10) reduction tube, (11) water pump, (12) sulfur generator, (13) potassium generator, (14) gas inlet, (15) transparent lid and cooling gas inlet, and (16) gas cylinders

Table 2 BFS gas and temperature profile

\begin{tabular}{llll}
\hline Time $(\min )$ & Temperature $\left({ }^{\circ} \mathrm{C}\right)$ & $\mathrm{N}_{2}(\%)$ & $\mathrm{CO}(\%)$ \\
\hline $0 \rightarrow 120$ & $25 \rightarrow 950$ & 100 & 0 \\
$120 \rightarrow 135$ & 950 & 100 & 0 \\
$135 \rightarrow 375$ & 950 & 60 & 40 \\
\hline
\end{tabular}

weight. The furnace has an inner diameter of $95 \mathrm{~mm}$; it employs a predetermined heating program, with a temperature and gas mixture set for each heating stage. The furnace can reach a temperature of $1100{ }^{\circ} \mathrm{C}$, and several gases are available in the BFS, including $\mathrm{N}_{2}$ and $\mathrm{CO}$, which were used in this study. The pre-set program used in this study with its temperature and gas profiles is shown in Table 2.

The reduction program in this study consisted of two main stages: The first stage lasted two hours, during which, $\mathrm{N}_{2}$ was introduced to the furnace at a flow rate of $15 \mathrm{l} / \mathrm{min}$ (NTP). The sample was heated until a temperature of $950^{\circ} \mathrm{C}$ was reached. The set temperature was maintained at $950{ }^{\circ} \mathrm{C}$ for another $15 \mathrm{~min}$ to ensure a stabilized and homogenous temperature profile inside the furnace. In the second stage, a reducing gas mixture of $\mathrm{N}_{2}$ and $\mathrm{CO}$ was used. The reducing atmosphere was maintained for $240 \mathrm{~min}$, with the furnace temperature being $950{ }^{\circ} \mathrm{C}$. After the second stage was completed, the $\mathrm{N}_{2}$ flow was introduced to the furnace at a flow rate of $10 \mathrm{l} / \mathrm{min}$ (NTP) to cool the sample while avoiding sample re-oxidation. The sample was observed during the test using a video camera and a mirror fixed at the top of the apparatus, adjusted to reflect the image of the sample inside BFS. The video camera recording was used to assess the swelling and cracking behavior of the briquette sample during the different stages of the program.

The briquette was assumed to be a perfect circular cylinder, and the final swelling was calculated based on the initial and final volume of the briquette using the following equation:

$\Delta V_{\text {briquette }}=\frac{A_{f} h_{f}-A_{i} h_{i}}{A_{i} h_{i}} \times 100 \%$

where $A_{f}$ is the final top surface area of the briquette after reduction, $h_{f}$ is the final briquette height after reduction, $A_{i}$ is the initial top surface area of the briquette before reduction, and $h_{i}$ is the initial briquette height before reduction.

Similarly, swelling during reduction was estimated based on information on the initial and final briquette dimensions along with briquette top surface area measurements from the video recording (i.e., as the top surface area increased to achieve the final surface area, the height of the briquette was assumed to increase proportionally to achieve the final briquette height). Finally, the briquettes were characterized for phase changes after reduction in the BFS using the same testing parameters employed in the XRD scanning of the briquettes pre-reduction.

\section{Results and Discussions}

\section{Side Stream Characterization}

Moisture content, apparent density, true density, and voids of side stream materials are listed in Table 3. It appears that most of side streams used have an average voidage of about $50 \%$, except for coke, which has a much higher porosity of about $81.70 \%$.

Figure 2 shows the particle size distribution of the side stream materials as well as the used rapid cement and GGBFS cement. Particle size distribution and side streams densities are used to determine the particle packing of the briquettes using EMMA software. The reference briquette particle packing determined using the modified Andreassen model with two distribution coefficients of 0.28 and 0.30 is shown in Figs. 3 and 4, respectively. The lines' proximity to one another shows that the briquette exhibits relatively good particle packing.

The chemical composition of each sample is presented in Table 4. It appears that harmful elements, especially $\mathrm{Zn}$ and $\mathrm{P}$, are in relatively low concentrations in the side stream materials. The highest sulfur content is found in the desulfurization scrap and alkalis in the rapid cement. 
Table 3 Moisture content and density of side stream material

\begin{tabular}{|c|c|c|c|c|c|}
\hline$\#$ & Raw material & $\begin{array}{l}\text { Moisture content } \\
\text { (db \%) }\end{array}$ & $\begin{array}{l}\text { Bulk density } \\
\left(\mathrm{kg} / \mathrm{m}^{3}\right)\end{array}$ & $\begin{array}{l}\text { Skeletal density } \\
\left(\mathrm{kg} / \mathrm{m}^{3}\right)\end{array}$ & Voidage (\%) \\
\hline 1 & Coarse pellet fines & 1.89 & 2579.10 & 4974.40 & 48.15 \\
\hline 2 & Fine pellet fines & 3.15 & 2688.50 & 4957.40 & 45.77 \\
\hline 3 & BF stock/cast house dust & 23.59 & 1089.93 & 2717.60 & 59.89 \\
\hline 4 & Coke dust & 0.06 & 364.75 & 1993.50 & 81.70 \\
\hline 5 & $\begin{array}{l}\text { Premix (60:40 steel scrap } \\
\text { and BF top dust) }\end{array}$ & 6.98 & 2076.14 & 4216.50 & 50.76 \\
\hline 6 & Briquette fines & 8.03 & 1725.73 & 3471.00 & 50.28 \\
\hline 7 & Desulfurization scrap & 15.01 & 1519.49 & 3878.30 & 60.82 \\
\hline 8 & Mill scale & 4.43 & 2676.13 & 5440.40 & 50.81 \\
\hline 9 & Steel scrap & 5.42 & 2406.33 & 4740.50 & 49.24 \\
\hline
\end{tabular}

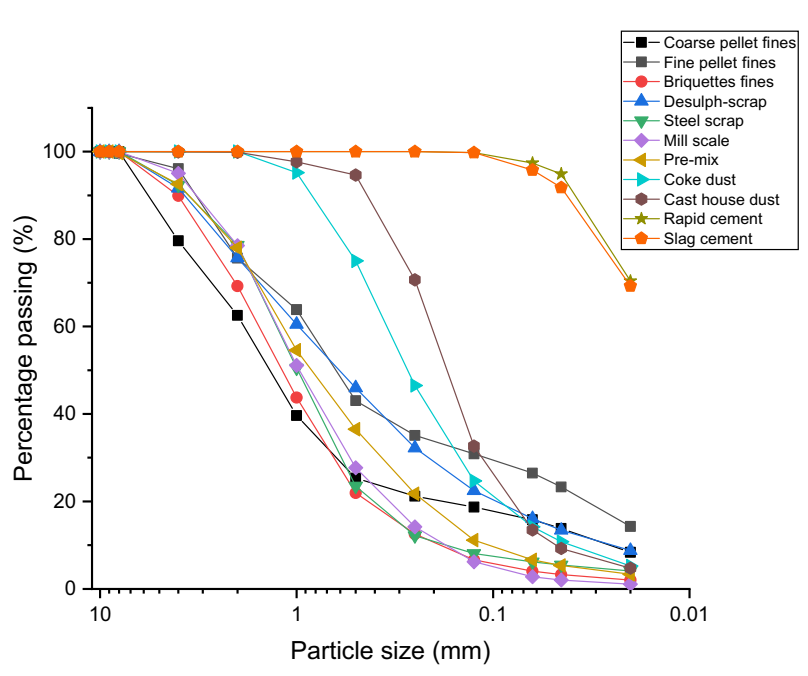

Fig. 2 Particle size distribution of side stream material
When replacing rapid and GGBFS cement with an LSG binder, the alkalis in the binder would be reduced at the expense of higher sulfur coming from the gypsum in the LSG binder. This may require special operational precautions depending on the process through which the briquettes are recycled because limited amount of sulfur should not be exceeded in binders intended to be used in steel mills [4]. Increased sulfur content coming from binders in briquettes used in processes like the BOF may result in increased costs related to further hot metal treatment and additional flux charge [5]. In blast furnace, more than half of the sulfur is transferred to the slag through reaction with calcium oxide to form calcium sulfide [8]. This also implies that increased sulfur input requires higher slag volume. This may eventually result in increased costs. Therefore, cost savings from side streams recycling should be carefully considered against resulting costs from binder use.

Detected phases of the samples are shown in Table 5. It appears that iron oxides are the dominating phases in the side stream material. Other phases present are calcite and quartz.
Fig. 3 EMMA particle packing for reference briquette with $q=0.28$

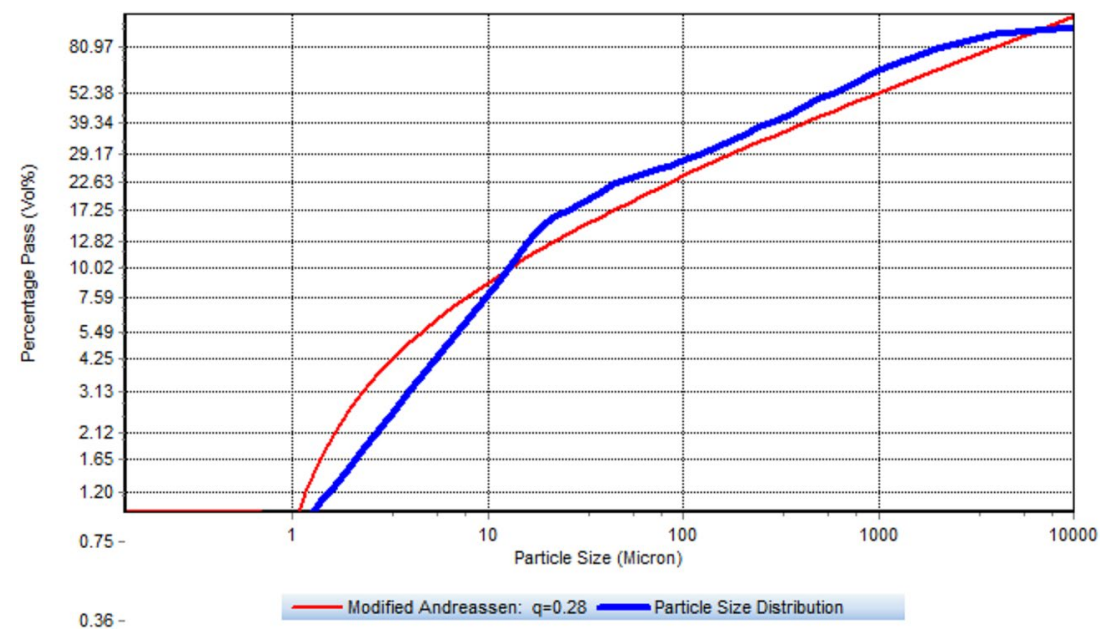


Fig. 4 EMMA particle packing for reference briquette with $q=0.30$

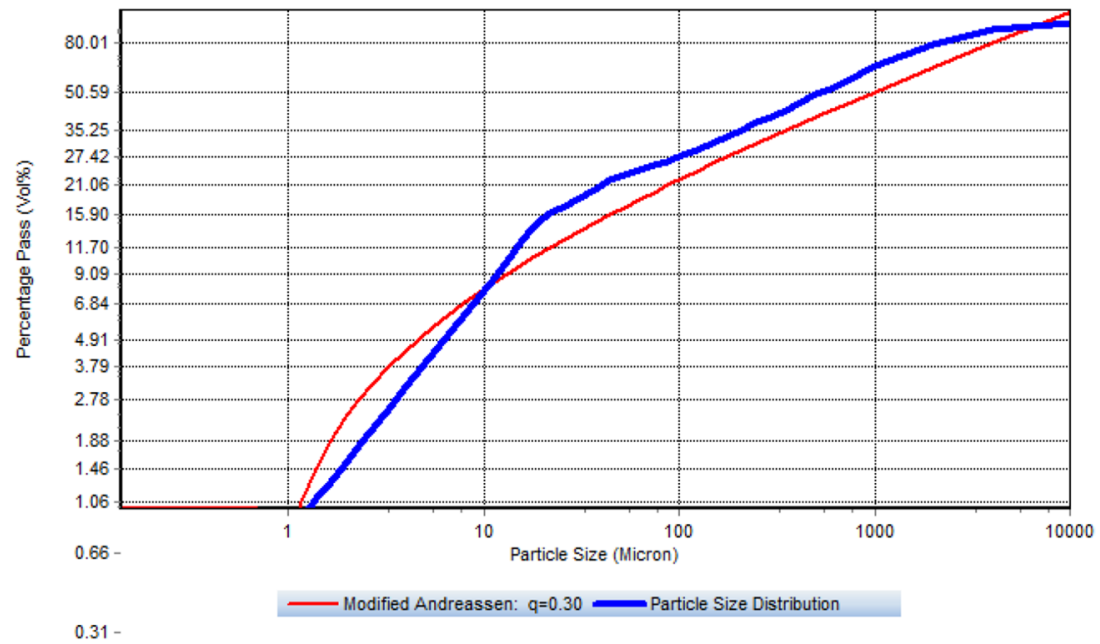

\section{Briquette Properties and Characterization}

\section{Compressive Strength}

Figure 5 shows the arithmetic mean value of two to three cold compression strength tests for each briquette recipe. The results show that the reference briquette exhibited an increase of strength over the 28-day curing period, which was expected due to the formation of $\mathrm{C}-\mathrm{S}-\mathrm{H}$. In the hydration of the Portland cement, around $70 \%$ of $\mathrm{C}_{3} \mathrm{~S}$ reacts during the first 28 days and the rest reacts over the course of a year. Moreover, $\beta-\mathrm{C}_{2} \mathrm{~S}$ behaves similarly, with $90 \%$ reacting over the course of the first year [45]. Therefore, the resulting strength of binding matrix is expected to increase further as more $\mathrm{C}-\mathrm{S}-\mathrm{H}$ are formed. The force load at which the 28-day-cured briquettes failed was similar to results obtained by other researchers [38].

For the briquette with the new LSG binder, it appears that the strength increased as the binder content increased in the initial $2^{\text {nd }}$ and 7 th days of tests. High early strength development is attributed to the formation of ettringite $\left(\mathrm{C}_{3} \mathrm{~A} \cdot 3 \mathrm{C} \overline{\mathrm{S}} \cdot 32 \mathrm{H}\right)$, a crystalline hydration product of the LSG binder [30], at a very early age (early hydration stage). Another hydration product that leads to an increase in strength is amorphous gibbsite $\left(\mathrm{AH}_{3}\right)$, which fills the voids between other phases, improving pore structure and increasing rigidity [46]. It is worth noting that LSG15 briquettes achieved comparable strength to the reference briquette on 2 and 7 days of test, while LSG20 binder developed significantly higher strength on 2 and 7 days of testing compared to the reference briquette.

However, after 28 days of curing, the strength of the LSG briquettes appeared to remain almost constant compared to the LSG briquettes cured for seven days. One exception was the 20\% LSG binder briquettes, which exhibited a slight decrease in strength on the 28 th day of test compared to the 7th day of compression test. One reason that could explain this behavior is the transformation of part of the ettringite into a monosulfate (AFm) [30]. In addition, a reduction in the water-to-binder ratio seems to be another factor that led to this reduction. In all briquette mixtures, a constant water content of $9.5 \%$ was used. Hence, with an increase in percentage of the binder being used (i.e., up to $20 \%$ binder), the water-to-binder ratio decreased, which might lead to a lower degree of hydration due to an insufficient amount of water available for hydration, as the water-to-binder ratio has a significant influence on the long-term strength development resulting from ladle slag hydration [47].

\section{Drop Test}

A drop test was performed to assess the drop damage resistance of the briquette. Figure 6 shows that, in the two-day drop test, the reference briquette had a drop damage resistance of around 39 on average. The LSG10 briquettes had a drop damage resistance of 5. On the other hand, all LSG15 and LSG20 briquettes showed better performance and were able to survive 50 drops without breaking. On the 7 th day of drop test, the drop damage resistance of the LSG10 briquettes increased to 10.5 and remained almost constant through the 28th day of drop test. Ref, LSG15, and LSG20 briquettes were all able to survive 50 drops - in both the 7 th and 28 th days of tests.

To further assess the LSG binder performance, the mass loss of the briquettes was compared against the reference briquette. It could be seen that the LSG15 and LSG20 briquettes were superior when compared to the reference briquettes during the two and seven days of drop tests, while the reference briquette exhibited less mass loss compared to the LSG briquettes on the 28th day of the drop test.

Similar to the compression strength test, the superior performance of the LSG briquettes in the two and seven 


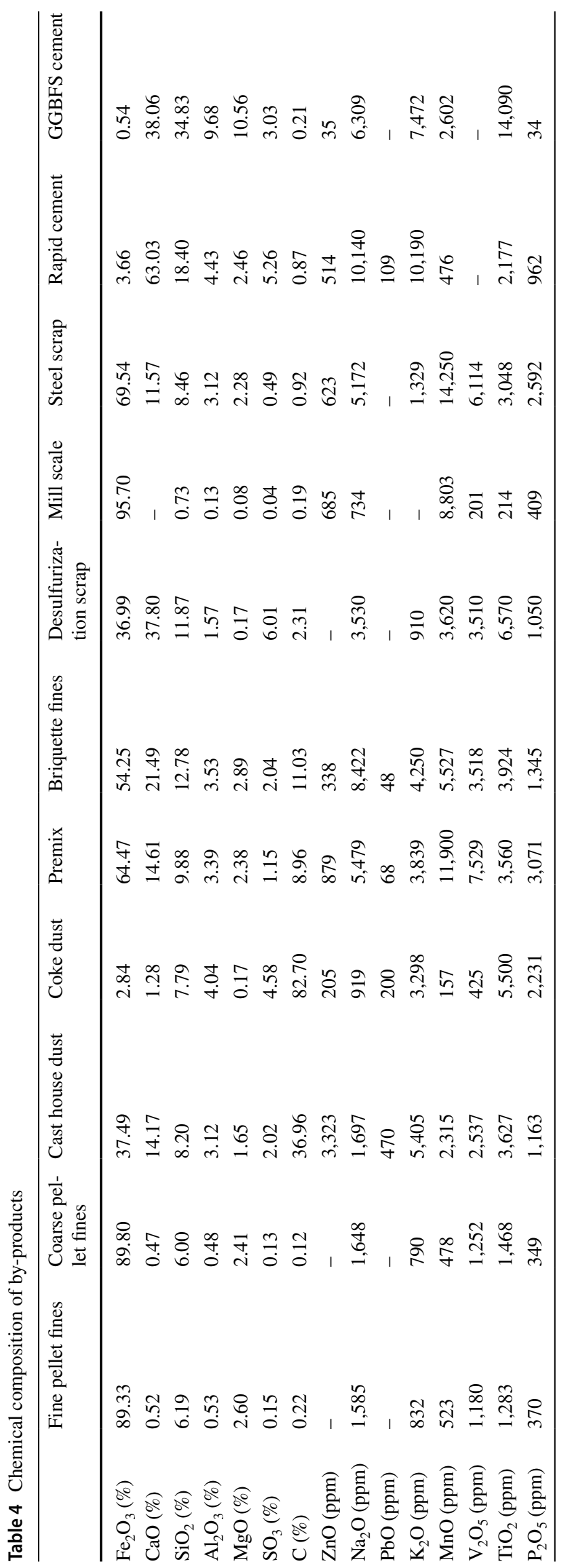


Table 5 Mineralogical phases of side stream materials

\begin{tabular}{ll}
\hline By-product & Detected phases \\
\hline Coarse pellet fines & Hematite-Magnetite-Quartz \\
Fine pellet fines & Hematite-Magnetite-Quartz \\
BF stock/cast house dust & Hematite-Magnetite and/or wüstite-Quartz \\
Premix & Hematite-Magnetite-Wüstite-Quartz \\
Briquette fines & Hematite-Calcite-Magnetite-Wüstite \\
Desulfurization scrap & Iron-Portlandite-Calcite-Magnetite- \\
& Quartz \\
Mill scale & Magnetite-Wüstite-Hematite-Iron \\
Steel scrap & Wüstite-Magnetite-Quartz-Calcite \\
Rapid cement & Alite-Larnite-Brownmillerite \\
\hline
\end{tabular}

days of drop tests can be attributed to the early strength development as a result of ettringite phase formation that contributed to the high early strength. This could be particularly useful when aiming to avoid briquette breaking during moving as well as extended curing periods, especially when considering that some plants have cementbonded briquettes cured in high humidity chambers for the first $24 \mathrm{~h}$ following briquette production [14]. The briquettes are taken outside of the plant afterward to be stored and continue their curing. Therefore, the fast strength development of the briquettes would be highly appreciated from this point of view as it would save costs and energy associated with high humidity chamber-curing. Overall, the LSG briquettes utilizing 15 and $20 \%$ binder showed comparable or even better mechanical performance than the reference briquette.

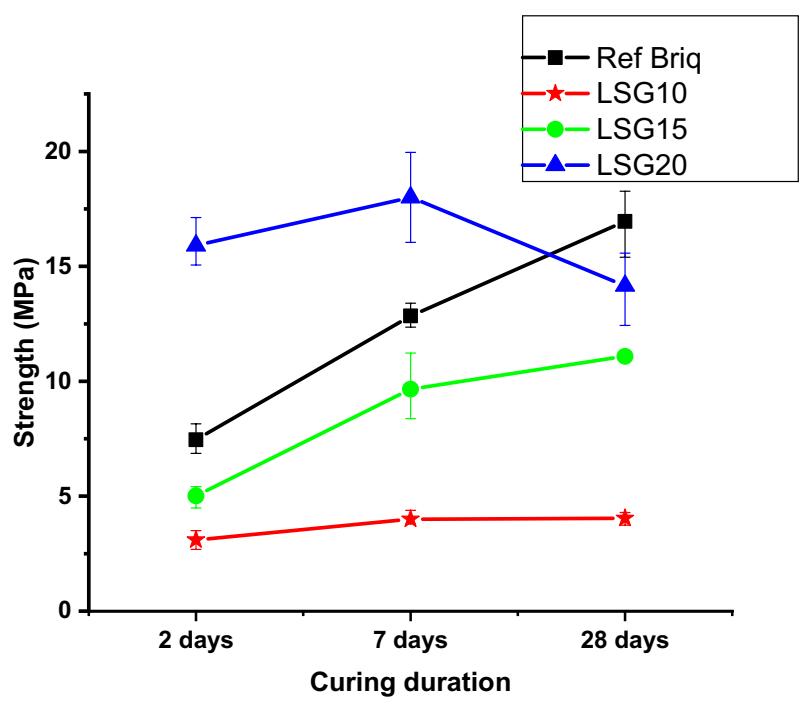

Fig. 5 Compression strength test results for different briquettes

\section{XRD}

Figure 7 shows the XRD patterns for the produced briquette shell and core. The phase characterization for the reference briquette, which utilizes a mixture of rapid and GGBFS cement as a binder, shows the formation of portlandite (calcium hydroxide, $\mathrm{Ca}(\mathrm{OH})_{2}$ ), an expected hydration phase [48], along with iron oxides phases previously detected in the raw material. The hydration of Portland cement results in the formation of nearly amorphous $\mathrm{C}-\mathrm{S}-\mathrm{H}$.

Gibbsite $\left(\mathrm{AH}_{3}\right)$ is an anticipated hydration product. It cannot be clearly detected through XRD because it does not have a well-defined crystal structure below $40{ }^{\circ} \mathrm{C}$. The weak peaks around $21^{\circ}$ may be attributed to its presence [46, 49].

From diffraction peaks, gypsum can be clearly identified. The reason for the presence of the unreacted gypsum might be due to the formation of $\mathrm{AH}_{3}$, which envelops other particles, preventing them from further hydration [45, 46]. Another reason might be that not enough water was available for the reaction with mayenite $\left(\mathrm{C}_{12} \mathrm{~A}_{7}\right)$ to produce $\mathrm{AH}_{3}$ according to Eq. 4. Similar diffraction peaks can be observed for the core and shell of the briquettes utilizing the LSG binder. However, the intensity of the characteristic peaks varies, decreasing as the LSG binder percentage increases.

Since the hydration took place at a temperature of around $20{ }^{\circ} \mathrm{C}$, the hydration and conversion reactions are considered as the following [50]:

$\mathrm{C}_{12} \mathrm{~A}_{7}+51 \mathrm{H}_{6} \mathrm{C}_{2} \mathrm{AH}_{8}+\mathrm{AH}_{3}$

$3 C_{2} A H_{8} 2 C_{3} A H_{6}+A H_{3}+9 H$

The conversion reaction from metastable $\mathrm{C}_{2} \mathrm{AH}_{8}$ to $\mathrm{C}_{3} \mathrm{AH}_{6}$ was expected to lead to a significant loss in strength as metastable hexagonal calcium aluminate hydrate was converted into stable cubic $\mathrm{C}_{3} \mathrm{AH}_{6}$, which has a considerably higher density. This conversion reaction leads to a volume change, causing a loss of strength due to an increase in the porosity of the binder $[47,51]$. Some literature has 


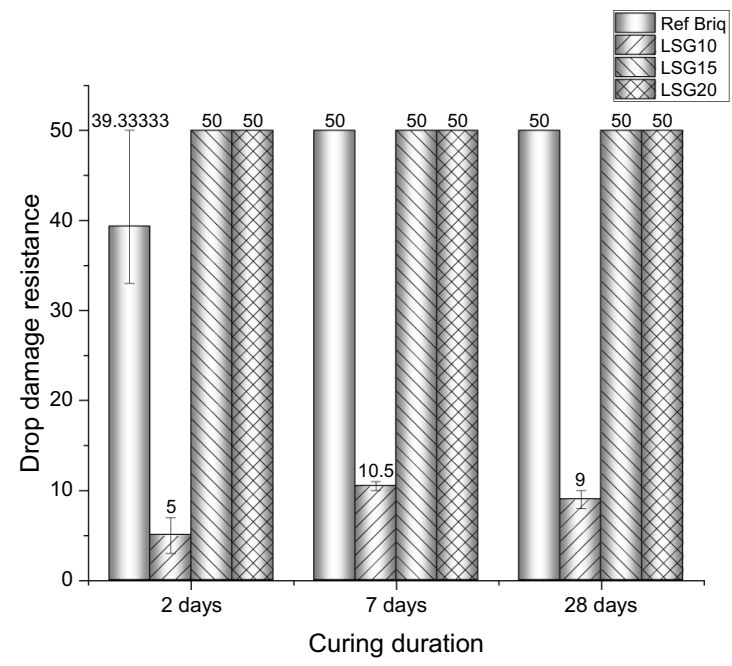

(a)

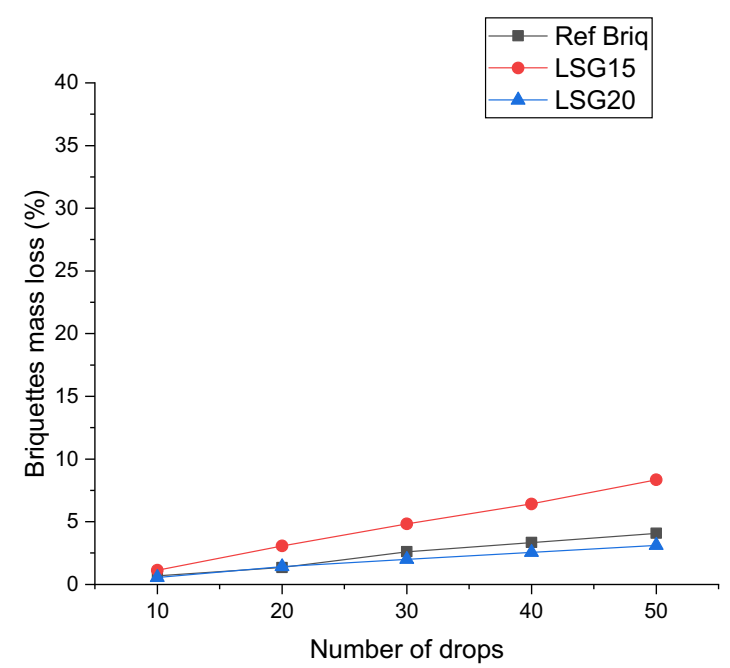

(c)

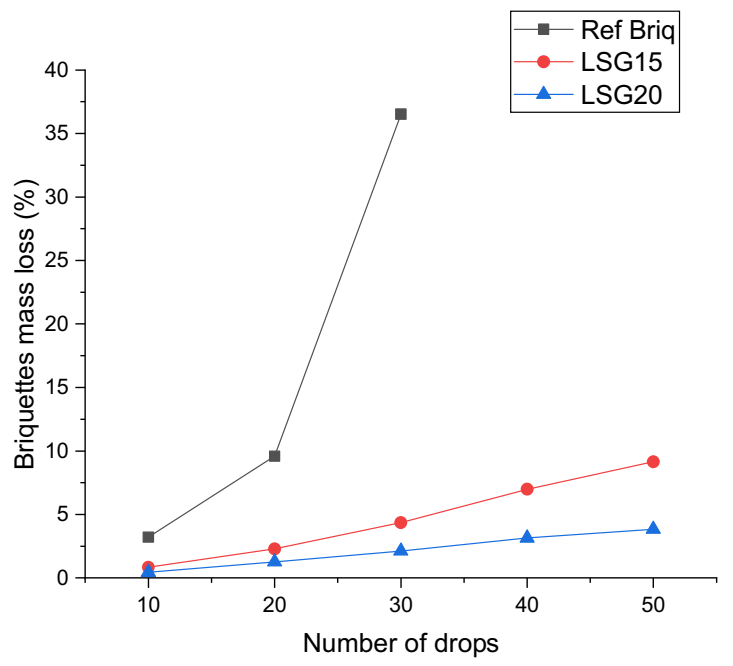

(b)

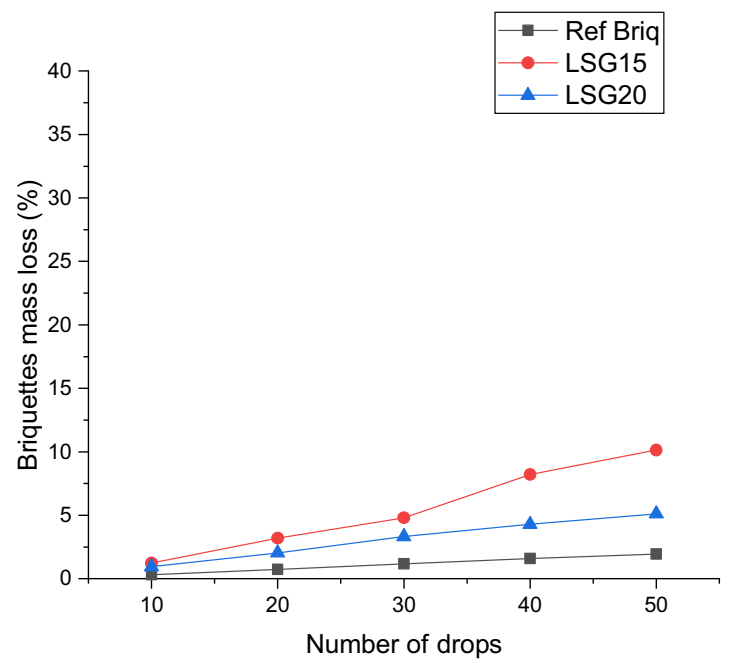

(d)

Fig. 6 a Drop damage resistance of briquettes, briquette mass loss after $\mathbf{b} 2$ days, $\mathbf{c} 7$ days, $\mathbf{d} 28$ days

reported the conversion reaction starting after $48 \mathrm{~h}$ when curing at $20^{\circ} \mathrm{C}$. The conversion reaction is accompanied by the release of water, which may further assist in the hydration of $\mathrm{C}_{12} \mathrm{~A}_{7}$ [50]. Previous research reported a decrease in strength on the 28th day of test as much as $50 \%$ of this strength developed on $3^{\text {rd }}$ day [47]. One reason why there was no sharp decline in the briquette strength on the 7 th and 28th days of test is the presence of gypsum, which prevented the formation of $\mathrm{C}_{3} \mathrm{AH}_{6}$, with ettringite being formed instead [34] through the following reaction:

$\mathrm{C}_{12} \mathrm{~A}_{7}+12 C \bar{S} \cdot 2 H+137 H \rightarrow 4 C_{3} A \cdot 3 C \bar{S} \cdot 32 H+3 A H_{3}$
Similar to gibbsite $\left(\mathrm{AH}_{3}\right)$, monosulfate $\left(\mathrm{C}_{4} \mathrm{~A} \overline{\mathrm{SH}}_{12}, \mathrm{AFm}\right)$ was likely not detected by XRD due to its poor crystallinity [49]. Although it is possible to detect AFm within a few days from the beginning of hydration, it could take months before AFm peaks are visible [45].

\section{FESEM}

The FESEM reference briquette polished section with an elemental detection map using EDS is shown in Fig. 8. The Fe distribution indicates the presence of iron oxide, which is likely to be hematite, as it was the dominating phase in the side stream materials, as determined by XRD. The $\mathrm{Ca}$ and 
Fig. 7 X-ray diffraction patterns for different briquettes at the core and shell

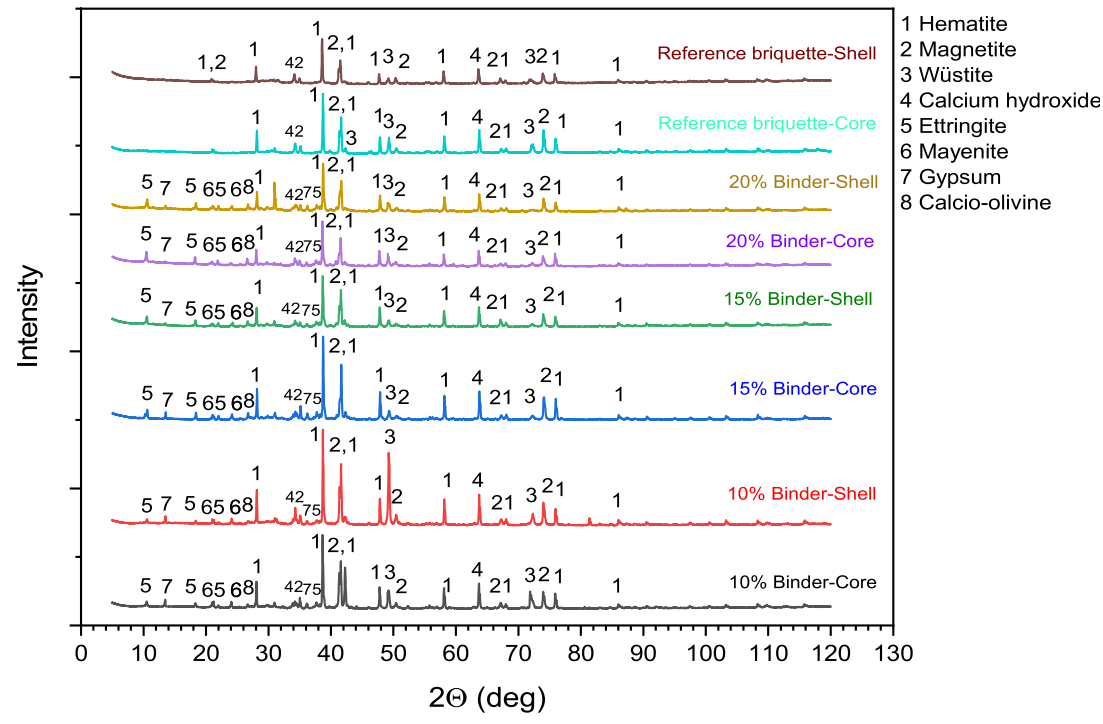

Si distributions indicate the $\mathrm{C}-\mathrm{S}-\mathrm{H}$ formation of a binding matrix that envelops smaller particles while connecting the by-product particles.

EDS mapping for the LSG20 briquette is shown in Fig. 9. The EDS maps clearly show the borders of the iron oxides from the side streams. $\mathrm{Ca}$ is well distributed around the iron oxide particles. Its presence with $\mathrm{Al}$ and $\mathrm{S}$ indicates that ettringite and monosulfate widely exist in the binding matrix. In certain parts of the map, especially the middle, $\mathrm{Al}$ exists with $\mathrm{Ca}$ but without a corresponding $\mathrm{S}$ in the same position, indicating the presence of mayenite $\left(\mathrm{C}_{12} \mathrm{~A}_{7}\right)$ and possibly $\mathrm{AH}_{3}$ in small amounts, as $\mathrm{AH}_{3}$ contains Ca from nanosized tricalcium aluminate hexahydrate [49].

A FESEM image of briquettes utilizing a 10\% LSG binder is shown in Fig. 10. Circular ettringite crystals were detected with their needle-like structure, identical to that identified in the previous research $[52,53] . \mathrm{AH}_{3}$ can be found in the shape of villous spherical particles that are $1-10 \mu \mathrm{m}$, which mainly contains $\mathrm{Al}$ and $\mathrm{O}$ along with a small amount of $\mathrm{Ca}$ [49]. They cannot be particularly detected in the FESEM images, possibly because they are incorporated into the ettringite matrix [46]. It is clear from the image how ettringite is forming a binding matrix around the spherical iron oxide particle.

\section{TGA-MS}

The influence of replacing rapid Portland cement and GGBFS cement with the LSG binder on the mass loss during heating was determined using thermogravimetric analysis (TGA). TGA and derivative thermogravimetry (DTG) curves for the reference briquette and LSG binder are given in Fig. 11. The thermogravimetric analysis/mass spectrometry (TGA-MS) curves for the reference briquette and LSG20 briquette are shown in Fig. 12. Due to the small size of the sample, reactions taking place during heating are assumed to be homogenous throughout the sample volume [54].

From the TGA-DTG curves, it appears that only a minor mass loss took place due to dehydration for both briquettes. For the LSG20 briquette, an obvious peak is observed at a temperature of around $150{ }^{\circ} \mathrm{C}$, which corresponds to the decomposition of ettringite $[30,55,56]$. Dehydration of gypsum also occurs at around $150{ }^{\circ} \mathrm{C}$ [46]. For the reference briquette, a small peak is observed around $450{ }^{\circ} \mathrm{C}$, which may correspond to the decomposition of $\mathrm{Ca}(\mathrm{OH})_{2}$ [57]. Additionally, a small peak observed around $380{ }^{\circ} \mathrm{C}$ can be attributed to the dehydration of $\mathrm{Mg}(\mathrm{OH})_{2}$ [58]. $\mathrm{AH}_{3}$ is expected to be detected at a temperature of around $270{ }^{\circ} \mathrm{C}$; however, it was not detected, as it might have converted into ettringite, via the reaction shown in Eq. 7 [46] or, a more likely possibility is that $\mathrm{AH}_{3}$ might have formed in a small fraction in the binder due to the need for an abundant amount of water for the reaction to take place, which was not the case with the briquettes made. The latter possibility is more likely.

$\mathrm{AH}_{3}+3 \mathrm{CH}+3 \mathrm{CS} \mathrm{S}_{2}+20 \mathrm{H} \rightarrow \mathrm{C}_{6} A \bar{S}_{3} H_{32}$

For both the reference briquette and LSG20 briquette, a peak can be observed around $550{ }^{\circ} \mathrm{C}$ and $750{ }^{\circ} \mathrm{C}$, which corresponds to the decomposition of $\mathrm{CaCO}_{3}$, which mainly comes from side streams in the case of the LSG binder [56, 57]. At $750{ }^{\circ} \mathrm{C}$, the peak may also correspond to a reduction in higher iron oxides [54].

It is likely that, in a composite containing carbon-bearing material, the reduction of iron oxides to metallic iron is initiated by a solid-solid reaction between carbon and iron oxide, and then reduction proceeds with the aid of the evolving $\mathrm{CO}$ gas from carbon gasification according to the following reactions $[59,60]$, 
Fig. 8 a FESEM image of polished section of reference briquette and maps showing distribution of $\mathbf{b ~ F e}, \mathbf{c ~ S i}, \mathbf{d ~ C a}$, and $\mathbf{e} \mathrm{S}$

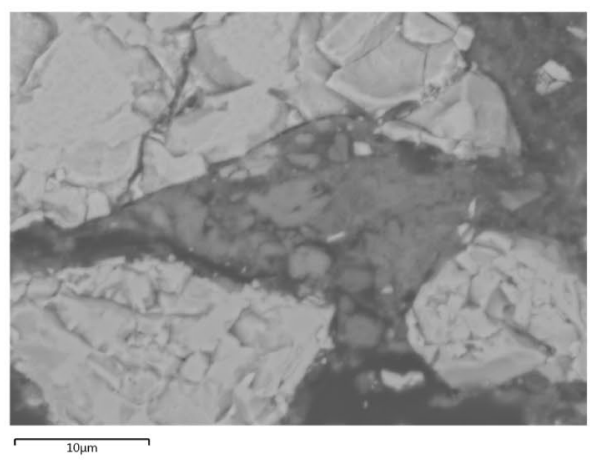

(a)

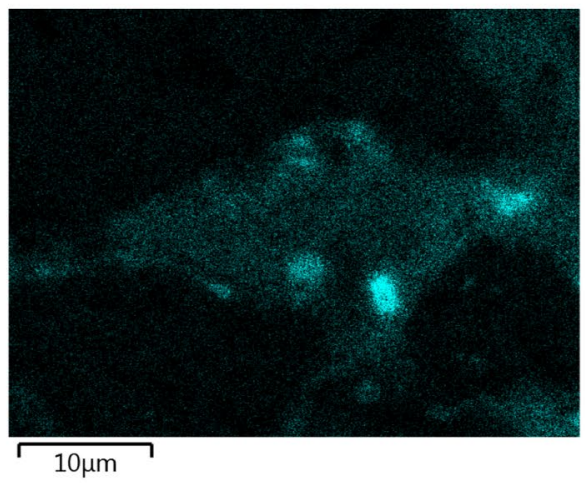

(c) $\mathrm{Si}$

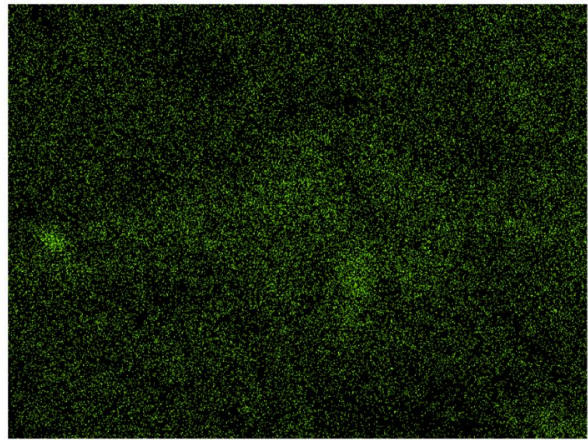

$10 \mu \mathrm{m}$

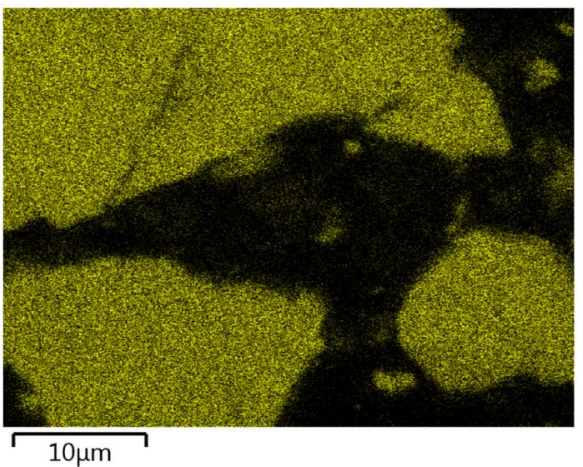

(b) $\mathrm{Fe}$

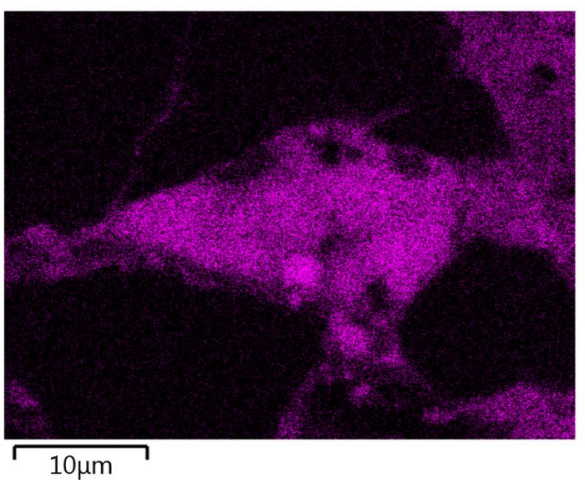

(d) $\mathrm{Ca}$

(e) $\mathrm{S}$

$\mathrm{Fe}_{x} \mathrm{O}_{y}(s)+\mathrm{CO}(\mathrm{g})=\mathrm{Fe}_{x} \mathrm{O}_{y-1}(s)+\mathrm{CO}_{2}(g)$

$\mathrm{CO}_{2}(g)+C(s)=2 \mathrm{CO}(g)$

Between temperatures of $490{ }^{\circ} \mathrm{C}$ and $770{ }^{\circ} \mathrm{C}$, slow and steady mass loss can be noted, which likely corresponds to a reduction in hematite according to Eq. 10 [61]:

$\mathrm{C}(s)+3 \mathrm{Fe}_{2} \mathrm{O}_{3}(s) \rightarrow 2 \mathrm{Fe}_{3} \mathrm{O}_{4}(s)+\mathrm{CO}(\mathrm{g})$
Moreover, the $\mathrm{CO}_{2}$ gas evolving from the dissociation of $\mathrm{CaCO}_{3}$ likely contributes to the gasification of carbon from the coke dust. At $800{ }^{\circ} \mathrm{C}$, a significant mass loss began to take place, which indicates the start of coke carbon gasification and the indirect reduction of iron oxides.

Almost full reduction of iron oxides to metallic iron has likely taken place with the reduction of wüstite to metallic iron starting around $750{ }^{\circ} \mathrm{C}$. However, the stepwise reduction from hematite and magnetite to wüstite and finally to metallic iron was not clearly observed in the TG curve because the heating 


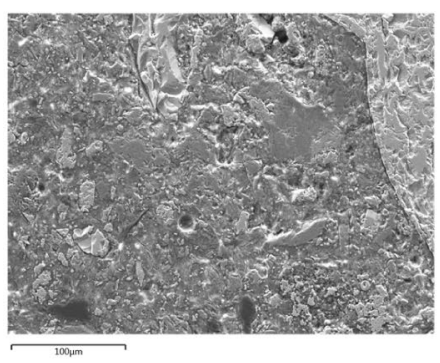

(a)

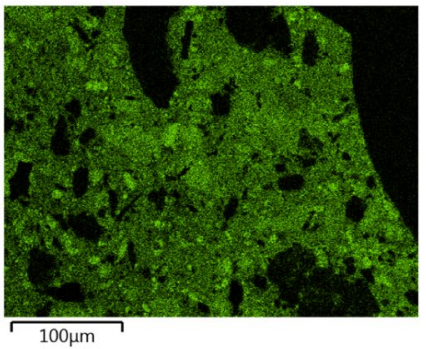

(d) $\mathrm{Ca}$

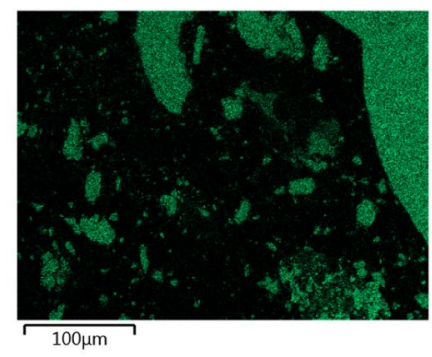

(b) $\mathrm{Fe}$

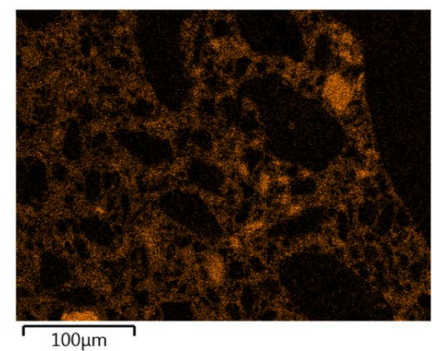

(e) $\mathrm{S}$

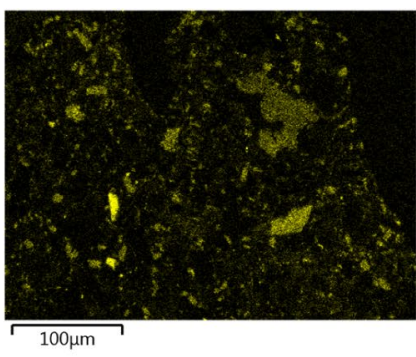

(c) $\mathrm{Si}$

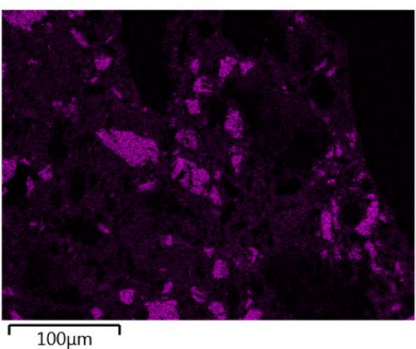

(f) Al

Fig. 9 a FESEM image of polished section of LSG20 briquette and EDS maps showing the distribution of b Fe, $\mathbf{c ~ S i , ~ d ~ C a , ~ e ~ S , ~ a n d ~} \mathbf{f}$ Al

rate was high and rapidly reached a high temperature required for the reduction of wüstite to metallic iron. A similar trend in TG reduction curves has been observed under equivalent conditions [59].

The first $\mathrm{H}_{2} \mathrm{O}$ peak in the range of $20^{\circ} \mathrm{C}$ to $380{ }^{\circ} \mathrm{C}$ likely corresponds to the dehydration of the $\mathrm{AFm}$ and $\mathrm{AFt}$ phases and the release of physically bound water [57]. A second peak is detected around $450-500{ }^{\circ} \mathrm{C}$, which obviously corresponds to the dehydration of $\mathrm{Ca}(\mathrm{OH})_{2}$ according to Eq. 11 [62]:

$\mathrm{Ca}(\mathrm{OH})_{2} \rightarrow \mathrm{CaO}+\mathrm{H}_{2} \mathrm{O}$

$\mathrm{CO}_{2}$ gas evolution started from temperature of $500^{\circ} \mathrm{C}$ up to $770{ }^{\circ} \mathrm{C}$, which corresponds with the decomposition of $\mathrm{CaCO}_{3}$ and the reduction of a higher amount of oxides according to Eq. 12 [62]:

$$
\mathrm{CaCO}_{3} \rightarrow \mathrm{CaO}+\mathrm{CO}_{2}
$$

When studying the behavior of self-reducing mixtures, coke gasification was found to take place at a temperature of $848-860{ }^{\circ} \mathrm{C}[59,61]$. In this study, the gasification appears to start around $800{ }^{\circ} \mathrm{C}$, which might be due to the presence of metallic iron, which acts as a catalysis for the gasification process $[59,63]$.

\section{Briquette Reduction and Swelling in BFS}

In this series of experiments, three briquettes were heated up to $950{ }^{\circ} \mathrm{C}$ in a $\mathrm{N}_{2}$ atmosphere, and the temperature was kept constant. After $135 \mathrm{~min}$ from the beginning of heating, reducing $\mathrm{CO}$ gas was introduced along with $\mathrm{N}_{2}$, and the reduction stage continued for another $240 \mathrm{~min}$. Fig. 13 shows the mass loss and swelling of the samples during the heating program. It can be seen from the figure that, $120 \mathrm{~min}$ after the program was initiated (when the temperature reached $950{ }^{\circ} \mathrm{C}$ in the inert atmosphere), the briquettes lost a significant amount of their mass. The reference briquette lost the least amount of mass (5.60\% of its initial mass), while the LSG20 briquette was the briquette that exhibited the greatest mass loss (8.56\% of its initial mass). Beside the loss of moisture, the steep mass loss of the LSG15 and LSG20 briquettes during the early stages of heating (below $250{ }^{\circ} \mathrm{C}$ ) can be attributed to ettringite disintegration and was only temperature-dependent, as it took place before a possible reduction could have taken place. Further mass loss in the briquettes during the heating stage can be attributed to the decomposition of $\mathrm{CaCO}_{3}$ and $\mathrm{Ca}(\mathrm{OH})_{2}$. After the reducing gas was introduced, a similar trend in mass loss was observed for all briquettes, mainly corresponding to the reduction of iron oxide in the briquette.

In terms of swelling, Fig. 13 shows contradicting behavior between the LSG briquettes and reference briquettes during the heating stage in $\mathrm{N}_{2}$. However, similar swelling trends among the briquettes were observed following the introduction of the reducing gas. The BFS reduction program resembles conditions at which the briquettes are more likely to exhibit catastrophic swelling, with the heating taking place non-isothermally in the first stage, reaching 


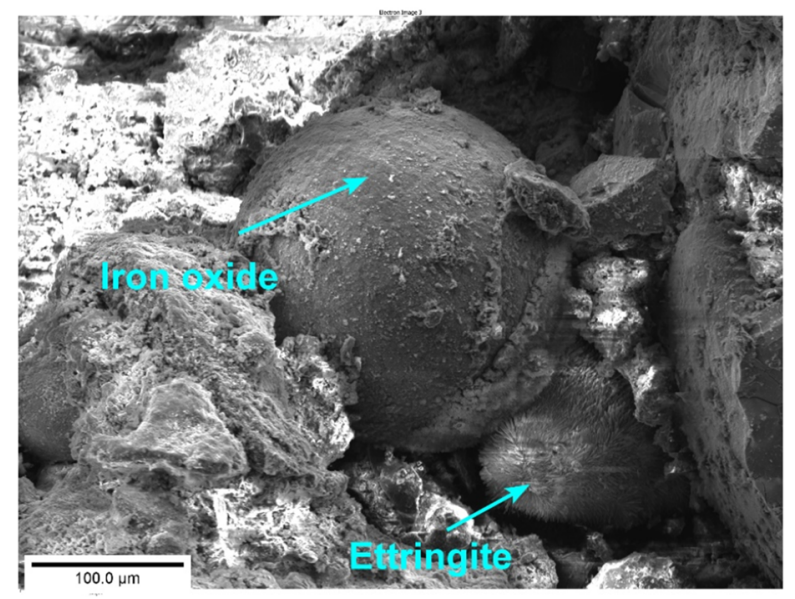

(a)

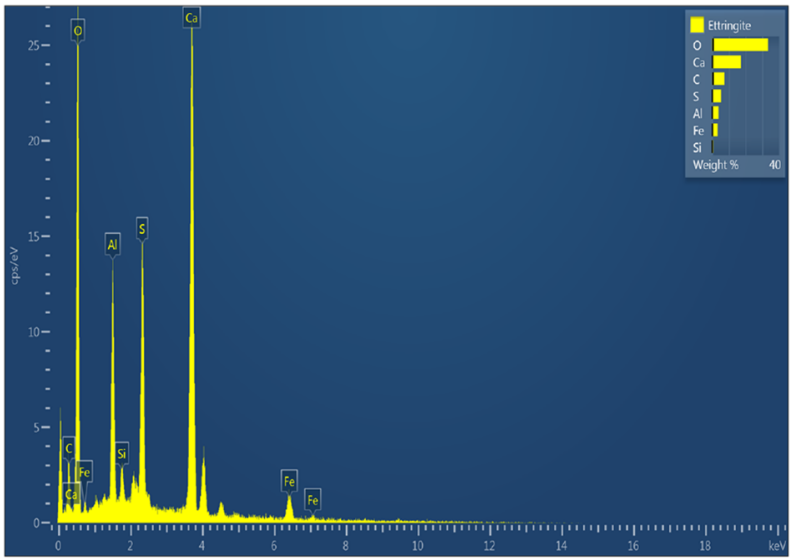

(b)

Fig. 10 a FESEM image of $10 \%$ LSG binder briquette and b EDS spectrum of ettringite crystal a maximum temperature of $950{ }^{\circ} \mathrm{C}$, and using $\mathrm{CO}$ as the reducing gas [64].

During the heating stage in $\mathrm{N}_{2}$, the LSG briquettes exhibited a slight contraction, with the volume of the LSG20 and LSG15 briquette decreasing $5.7 \%$ and $0.6 \%$, respectively. On the other hand, the reference briquette volume exhibited a $16.3 \%$ increase of its initial volume. Such observation indicates that the ettringite binder decomposition is accompanied by slight briquette volume shrinkage. On the other hand, increased swelling was observed in the LSG briquettes as well as the reference briquette after the introduction of the reducing atmosphere. This can be mainly attributed to the reduction of iron oxides present in all three tested briquettes (hematite to magnetite to wüstite and, finally, to metallic iron).

When heating the reference briquette in $\mathrm{N}_{2}$ up to $950{ }^{\circ} \mathrm{C}$, the $\mathrm{C}-\mathrm{S}-\mathrm{H}$ gel is converted to $\mathrm{C}_{2} \mathrm{~S}$ and $\mathrm{CaO}$, which supposedly reacts with the iron oxides to form calcium ferrite $(\mathrm{CF})$ and calcium silicoferrite $\left(\mathrm{C}_{3} \mathrm{SF}_{3}\right)$ [64]. When introducing $\mathrm{CO}$ reducing gas, metastable $\mathrm{Fe}_{3} \mathrm{C}$ forms and later oxidizes to $\mathrm{Fe}$. Evolving gases may contribute to further swelling. The reactions can be written as [64]

$$
\begin{aligned}
3 \mathrm{FeO}+5 \mathrm{CO} & \rightarrow \mathrm{Fe}_{3} \mathrm{C}+4 \mathrm{CO}_{2} \\
\mathrm{Fe}_{3} \mathrm{C}+\mathrm{FeO} & \rightarrow 4 \mathrm{Fe}+\mathrm{CO} \\
\mathrm{Fe}_{3} \mathrm{C}+\mathrm{CO}_{2} & \rightarrow 3 \mathrm{Fe}+2 \mathrm{CO}
\end{aligned}
$$

Images of the briquettes post reduction in the BFS are shown in Fig. 14. It appears that the reference briquette exhibited more swelling and developed more cracks compared to the LSG briquettes.
Fig. 11 TGA-DTG curves for reference and LSG20 briquettes

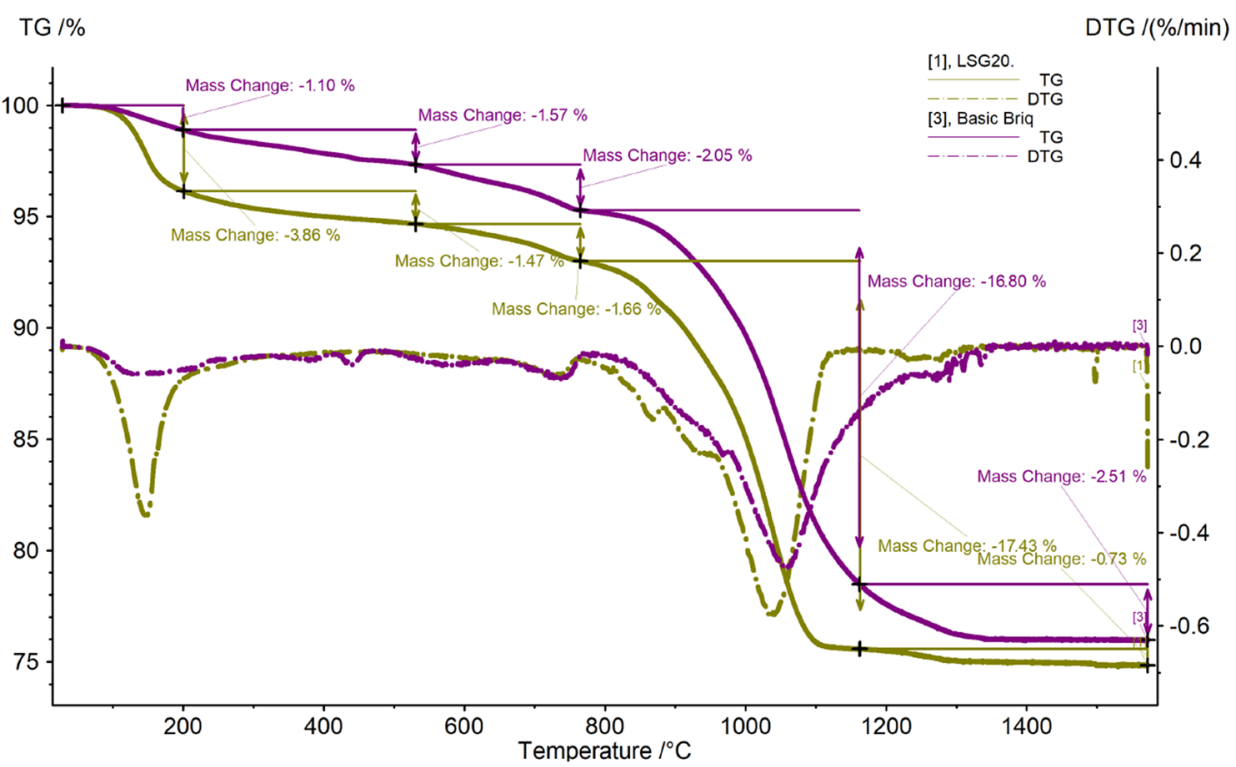




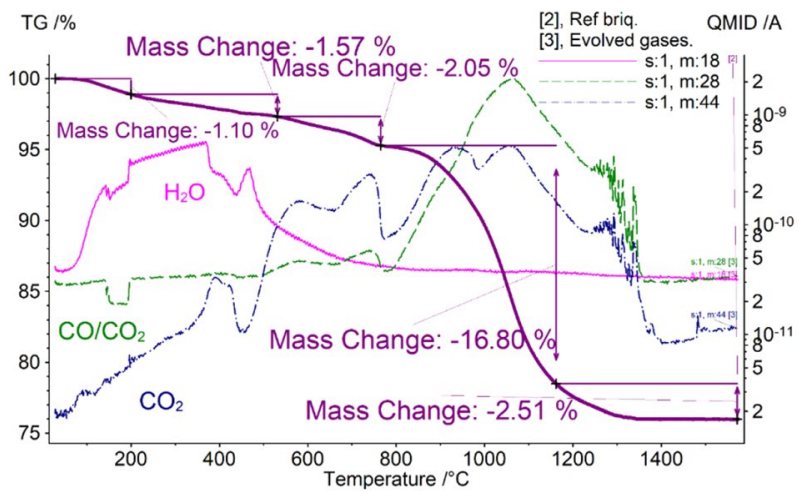

(a)

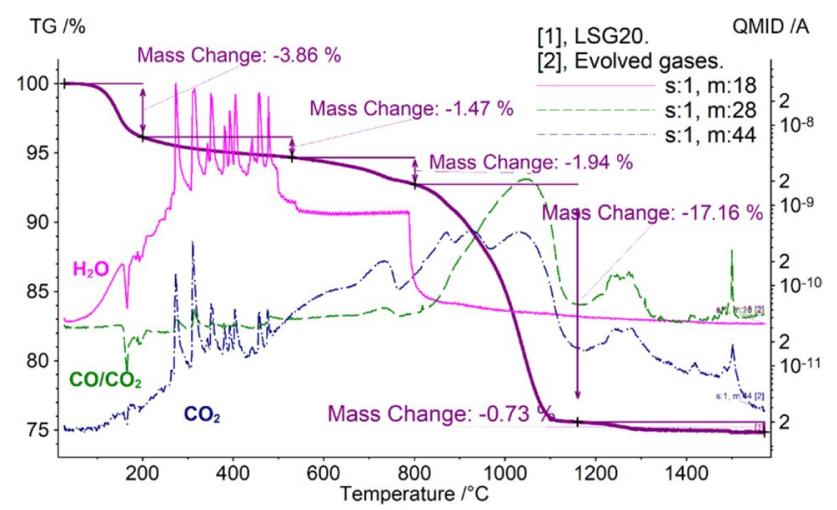

(b)

Fig. 12 TGA-MS for a reference briquette and b LSG20 briquette

To examine the briquette structure post reduction, FESEM-EDS was used. Pieces from the fracture surface of the briquette were placed on a carbon tape and platinumcoated. Figure 15 shows the formation of fibrous metallic iron in the reference briquette post reduction. The metallic fibrous iron contributes to the swelling by exerting an internal stress on the briquette structure, pushing against its surrounding. On the other hand, no fibrous iron was formed in the LSG20 briquette. Iron takes the form of closely packed thick and irregular tubes with a coarse outer texture. Differences between reference and LSG20 briquettes with respect to the structure of formed iron might have contributed to the lower swelling in the LSG briquettes.

A compression strength test was carried out for the briquettes post reduction in the BFS. All tested briquettes virtually lost all their strength after reduction. The force at which the briquettes exhibited failure was $329.8,215.5$, and $57.6 \mathrm{~N}$ for the reference, LSG20, and LSG15 briquette, respectively. The briquettes exhibited significant strength loss when heated in the nitrogen atmosphere due to the destruction of the bonding matrix. Strength loss became even more drastic when heating took place in the reducing atmosphere, since the destruction of the binding matrix is coupled with the

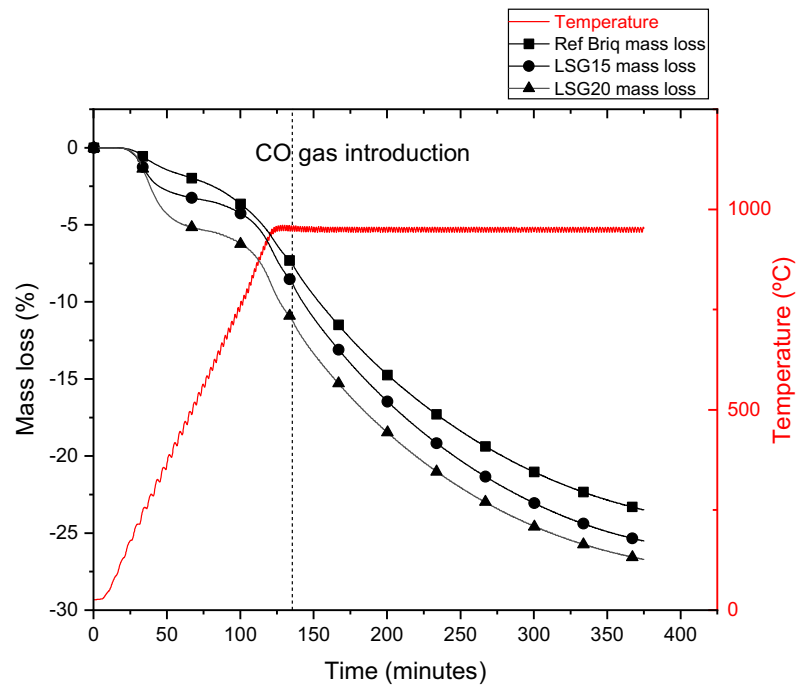

(a)

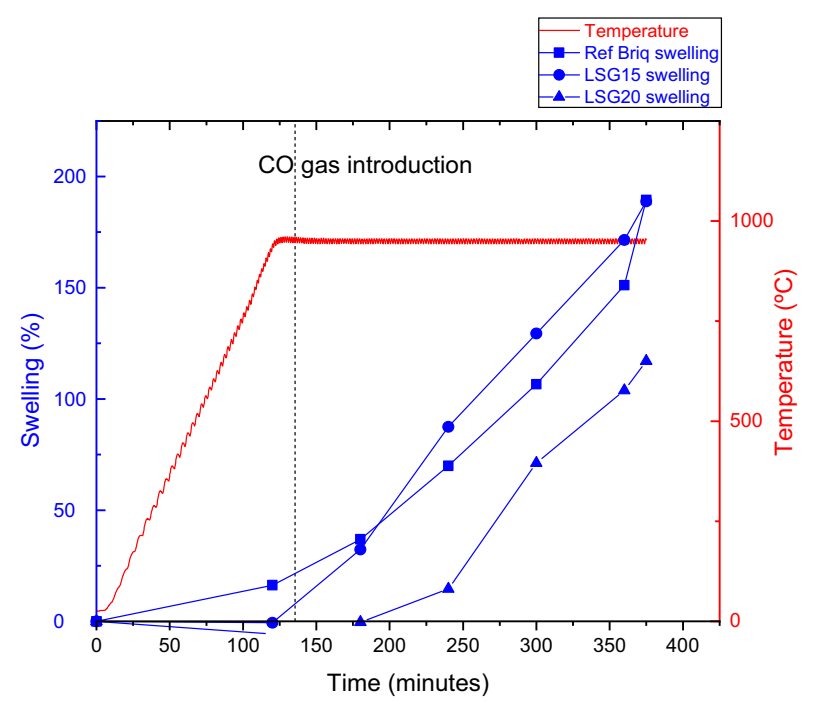

(b)

Fig. 13 Mass loss (a) and swelling (b) in BFS for reference, LSG15, and LSG20 briquettes

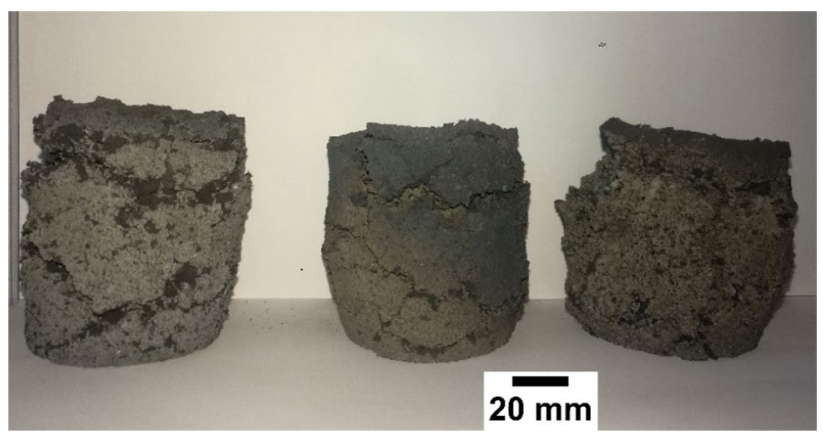

Fig. 14 Briquettes post reduction in the BFS. From left to right: reference briquette, LSG20, and LSG15 


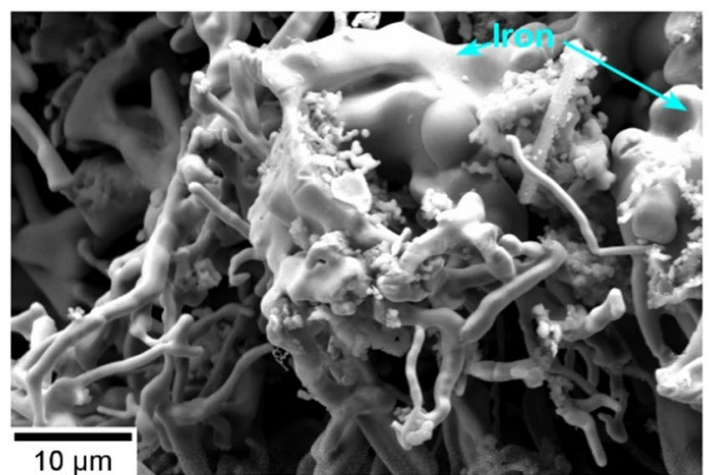

(a)

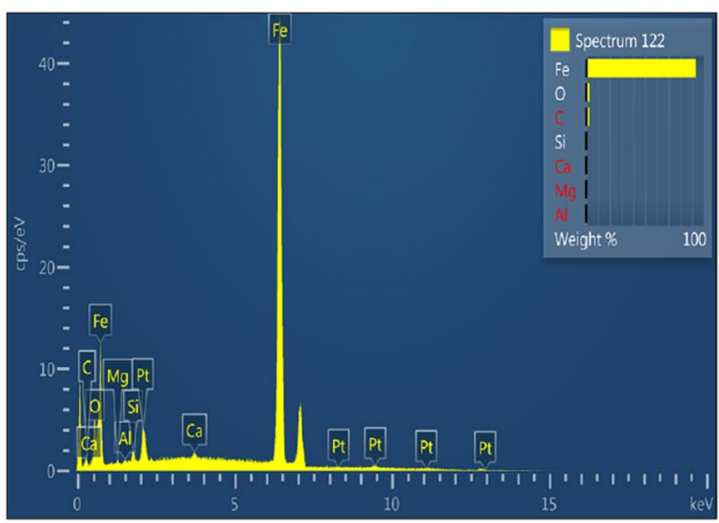

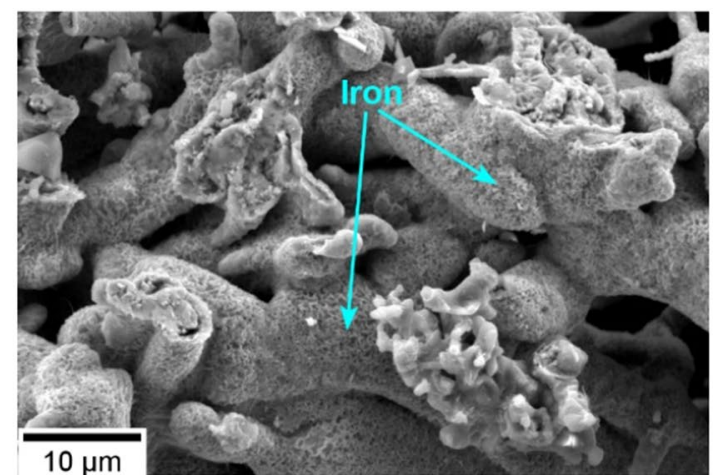

(b)

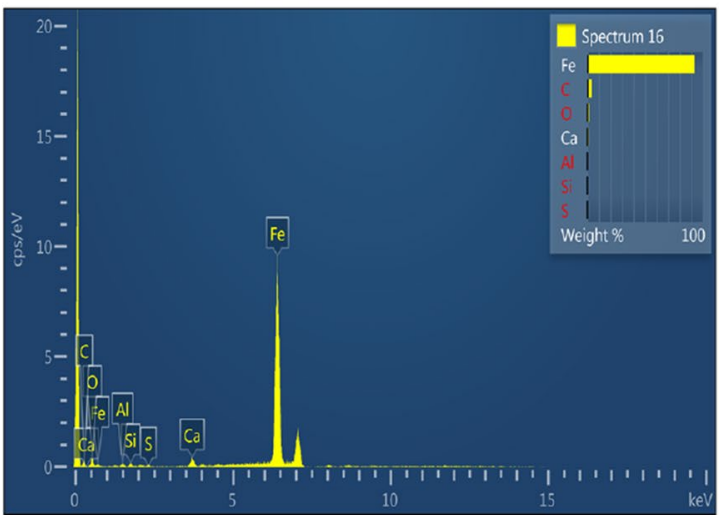

Fig. 15 FESEM image and right point EDS analysis post reduction in BFS at $950{ }^{\circ} \mathrm{C}$ in $\mathrm{N}_{2}: \mathrm{CO}$ atmosphere (60:40) for a reference briquette and b LSG20 briquette

transformation of the aggregate [38]. The results also show that binder content plays a major role in retaining briquettes strength after heating as LSG20 had significantly higher strength compared to LSG15.

$\mathrm{XRD}$ for the briquettes post reduction was carried out for the reference, LSG15, and LSG20 briquettes. The detected phases are shown in Fig. 16. It appears that most iron oxides reduced to metallic iron; however, some wüstite remains unreduced. Mayenite could be detected in the LSG briquettes, indicating that part of mayenite did not completely hydrate and remained throughout the curing as well as after reduction. It also appears that $\mathrm{C}-\mathrm{S}-\mathrm{H}$ converted into $\mathrm{Ca}_{2} \mathrm{SiO}_{4}$ and partly reacted with iron, forming $\mathrm{CaFe}_{2} \mathrm{O}_{4}$.

\section{Conclusions}

The performance of cold-bonded briquettes utilizing ettringite-based binders was evaluated in terms of their mechanical and thermal characteristics. Cold-bonded briquettes produced using 10,15 , and $20 \%$ of ettringite-based binder (LSG) were compared against a reference briquette produced using ground granulated blast furnace slag and rapid

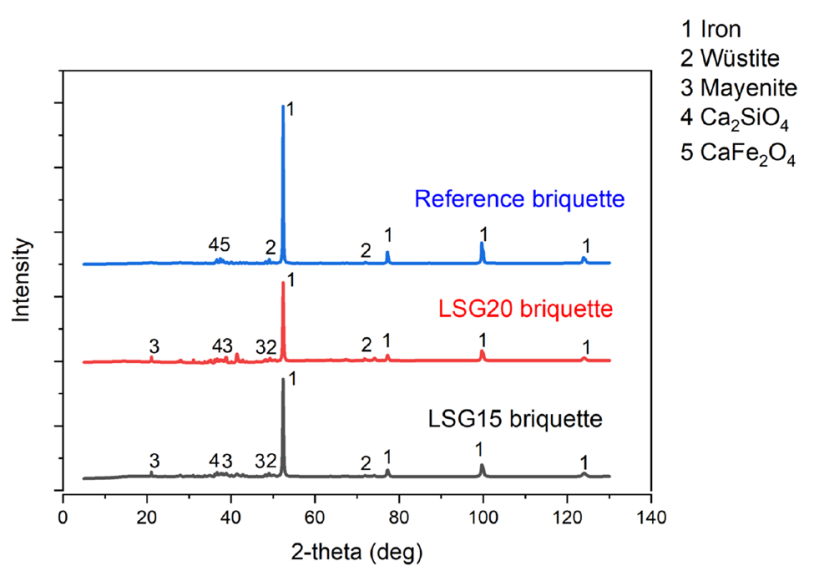

Fig. $16 \mathrm{X}$-ray diffraction patterns for briquettes post reduction in the BFS

cement. Briquettes produced using 15 and 20\% LSG binder exhibited rapid early strength development after being cured in ambient conditions. They were superior to the reference briquettes in terms of strength and drop damage resistance after the $2^{\text {nd }}$ and 7 th days of curing and had comparable performance after the 28th day of curing. 
The high-temperature thermal behavior of the briquettes was assessed using TGA-DTG-MS for a small sample size in an $\mathrm{Ar}$ atmosphere. Full-size briquettes of each type were also tested in a reducing atmosphere in a blast furnace simulator. The TG-MS results showed that the ettringite phase in the LSG briquettes dissociated at around $150{ }^{\circ} \mathrm{C}$. Meanwhile, $\mathrm{CaCO}_{3}$ dissociated above $770{ }^{\circ} \mathrm{C}$ and produced $\mathrm{CO}_{2}$ gas, which contributed to the gasification of carbon in coke and, subsequently, the reduction of the iron oxides. In terms of swelling, the reference briquette exhibited significant swelling when heated in the $\mathrm{N}_{2}$ atmosphere up to $950{ }^{\circ} \mathrm{C}$ compared to the briquettes with 15 and $20 \%$ LSG binder, which exhibited slight shrinkage instead. Upon the introduction of the reducing gas at $950{ }^{\circ} \mathrm{C}$, both briquette types exhibited major swelling. However, the briquette with $20 \%$ LSG binder exhibited less swelling compared to the reference briquette. The main reason for the relatively increased swelling in the reference briquette is the formation of fibrous metallic iron, which pushes against its surrounding, as confirmed by the FESEM images.

Overall, the LSG binder is a potentially good alternative to conventional cement in briquette making due to its early strength development and reduced swelling. Moreover, the LSG binder offers a chance to reduce $\mathrm{CO}_{2}$ emissions, since the LSG binder mostly consists of ladle slag, another side stream from the iron and steelmaking industry. However, sulfur content originating from gypsum and potential lowtemperature disintegration due to the dissociation of ettringite may limit the use of briquettes in some industrial applications, such as the BF.

Acknowledgements The authors would like to acknowledge Mr. Tommi Kokkonen from the Process Metallurgy research unit at the University of Oulu for his technical support. They would also like to acknowledge the Centre for Material Analysis (CMA) at the University of Oulu for their assistance in the chemical and mineralogical characterization. This work was supported by Business Finland through SYMMET Project (4236/31/2018), Kvantum institute (University of Oulu), and Academy of Finland [Grant Nos. 322085, 329477 and 326291]. The Finnish Cultural Foundation (Grant No.: 60212342/2021), Walter Ahlström Foundation, and Olvi Foundation are acknowledged for their financial support.

Funding Open Access funding provided by University of Oulu including Oulu University Hospital.

\section{Declarations}

Conflict of interest On behalf of all authors, the corresponding author states that there is no conflict of interest.

Open Access This article is licensed under a Creative Commons Attribution 4.0 International License, which permits use, sharing, adaptation, distribution and reproduction in any medium or format, as long as you give appropriate credit to the original author(s) and the source, provide a link to the Creative Commons licence, and indicate if changes were made. The images or other third party material in this article are included in the article's Creative Commons licence, unless indicated otherwise in a credit line to the material. If material is not included in the article's Creative Commons licence and your intended use is not permitted by statutory regulation or exceeds the permitted use, you will need to obtain permission directly from the copyright holder. To view a copy of this licence, visit http://creativecommons.org/licenses/by/4.0/.

\section{References}

1. Wang H, Zhao W, Chu M et al (2017) Current status and development trends of innovative blast furnace ironmaking technologies aimed to environmental harmony and operation intellectualization. J Iron Steel Res Int 24:751-769. https://doi.org/10.1016/ S1006-706X(17)30115-2

2. Das B, Prakash S, Reddy PSR, Misra VN (2007) An overview of utilization of slag and sludge from steel industries. Resour Conserv Recycl 50:40-57. https://doi.org/10.1016/j.resconrec. 2006.05.008

3. Singh M, Björkman B (2004) Effect of processing parameters on the swelling behaviour of cement-bonded briquettes. ISIJ Int 44:59-68. https://doi.org/10.2355/isijinternational.44.59

4. Pietsch W (2002) Agglomeration processes: phenomena, technologies, equipment. Wiley-VCH, Weinheim

5. Koros PJ (2003) Dusts, scale, slags, sludges... not wastes, but sources of profits. Metall Mater Trans B 34:769-779

6. Singh AKP, Raju MT, Jha U (2011) Recycling of Basic Oxygen Furnace (BOF) sludge in iron and steel works. Int J Environ Technol Manag 14:19. https://doi.org/10.1504/IJETM.2011. 039255

7. Qiu G, Jiang T, Li H, Wang D (2003) Functions and molecular structure of organic binders for iron ore pelletization. Colloids Surf Physicochem Eng Asp 224:11-22. https://doi.org/10.1016/ S0927-7757(03)00264-4

8. Geerdes M, Chaigneau R, Kurunov I et al (2015) Modern blast furnace ironmaking: an introduction. IOS Press, Amsterdam

9. Kasai A, Matsui Y (2004) Lowering of thermal reserve zone temperature in blast furnace by adjoining carbonaceous material and iron ore. ISIJ Int 44:2073-2078. https://doi.org/10.2355/isijintern ational.44.2073

10. Robinson R, Ökvist LS (2003) Recycling of by-product pellets as burden in the blast furnace process: a lab and pilot scale investigation. In: METEC Congress 2003. Düsseldorf, pp 370-375

11. Landow MP, Martinez M, Barnett T (1997) The recycling of waste oxides at Great Lakes Division. National Steel Corporation, Iron and Steel Society, Warrendale, PA (United States), United States

12. Kemppainen A, Iljana M, Heikkinen E-P et al (2014) Reduction behavior of cold-bonded briquettes under simulated blast furnace conditions. ISIJ Int 54:1539-1545. https://doi.org/10.2355/isiji nternational.54.1539

13. De Belie N, Soutsos M, Gruyaert E (2018) Properties of fresh and hardened concrete containing supplementary cementitious materials: state-of-the-art report of the RILEM Technical Committee 238-SCM, Working Group 4. Springer, Cham

14. Sundqvist Ökvist L, Jonsson K, Lampinen H, Eriksson L (1999) Recycling of in-plant fines as cold-bonded agglomerates. Belgium, Brussels

15. Singh M, Björkman B (1999) Cold bond agglomerates of iron and steel plant byproducts as burden material for blast furnaces. In: Proceedings of the REWAS'99: global symposium on recycling, waste treatment and clean technology, pp 1539-1548

16. Drobíková K, Plachá D, Motyka O et al (2016) Recycling of blast furnace sludge by briquetting with starch binder: waste gas from 
thermal treatment utilizable as a fuel. Waste Manag 48:471-477. https://doi.org/10.1016/j.wasman.2015.11.047

17. Mousa EA, Ahmed HM, Wang C (2017) Novel approach towards biomass lignin utilization in ironmaking blast furnace. ISIJ Int 57:1788-1796. https://doi.org/10.2355/isijinternational.ISIJI NT-2017-127

18. Echterhof T, Willms T, Preiss S et al (2019) Fabrication of agglomerates from secondary raw materials reinforced with paper fibres by stamp pressing process. Appl Sci 9:3946. https://doi.org/ 10.3390/app9193946

19. Babanin VI, Eremin AY, Bezdezhskii GN (2007) Development and introduction of a new technology for briquetting finely divided materials with sodium silicate. Metallurgist 51:6

20. Choi S, Kim J-M, Han D, Kim J-H (2016) Hydration properties of ladle furnace slag powder rapidly cooled by air. Constr Build Mater 113:682-690. https://doi.org/10.1016/j.conbuildmat.2016. 03.089

21. Shi C (2002) Characteristics and cementitious properties of ladle slag fines from steel production. Cem Concr Res 32:459-462. https://doi.org/10.1016/S0008-8846(01)00707-4

22. Adolfsson D, Robinson R, Engström F, Björkman B (2011) Influence of mineralogy on the hydraulic properties of ladle slag. Cem Concr Res 41:865-871. https://doi.org/10.1016/j.cemconres.2011. 04.003

23. Adesanya E, Ohenoja K, Kinnunen P, Illikainen M (2017) Properties and durability of alkali-activated ladle slag. Mater Struct 50:255. https://doi.org/10.1617/s11527-017-1125-4

24. Shi C, Hu S (2003) Cementitious properties of ladle slag fines under autoclave curing conditions. Cem Concr Res 33:1851-1856. https://doi.org/10.1016/S0008-8846(03)00211-4

25. Papayianni I, Anastasiou E (2012) Effect of granulometry on cementitious properties of ladle furnace slag. Cem Concr Compos 34:400-407. https://doi.org/10.1016/j.cemconcomp.2011.11.015

26. Rađenović A, Malina J, Sofilić T (2013) Characterization of ladle furnace slag from carbon steel production as a potential adsorbent. Adv Mater Sci Eng 2013:1-6. https://doi.org/10.1155/2013/ 198240

27. Adolfsson D, Engström F, Robinson R, Björkman B (2011) Cementitious phases in ladle slag. Steel Res Int 82:398-403. https://doi.org/10.1002/srin.201000176

28. British Standards Institution (1986) Methods for determination of particle size distribution. Part 1: Guide to powder sampling (BS 3406-1:1986). British Standards Institution (BSI), London

29. British Standards Institution (1998) Tests for mechanical and physical properties of aggregates. Part 3: Determination of loose bulk density and voids (BS EN 1097 :1998). British Standards Institution (BSI), London

30. Nguyen H, Adesanya E, Ohenoja K et al (2019) Byproduct-based ettringite binder: a synergy between ladle slag and gypsum. Constr Build Mater 197:143-151. https://doi.org/10.1016/j.conbuildmat. 2018.11.165

31. Pelletier L, Winnefeld F, Lothenbach B (2010) The ternary system Portland cement-calcium sulphoaluminate clinker-anhydrite: hydration mechanism and mortar properties. Cem Concr Compos 32:497-507. https://doi.org/10.1016/j.cemconcomp.2010.03.010

32. Möschner G, Lothenbach B, Figi R, Kretzschmar R (2009) Influence of citric acid on the hydration of Portland cement. Cem Concr Res 39:275-282. https://doi.org/10.1016/j.cemconres.2009. 01.005

33. Nguyen H, Kinnunen P, Carvelli V et al (2019) Strain hardening polypropylene fiber reinforced composite from hydrated ladle slag and gypsum. Compos Part B Eng 158:328-338. https://doi.org/ 10.1016/j.compositesb.2018.09.056

34. Nguyen H, Staudacher M, Kinnunen P et al (2019) Multi-fiber reinforced ettringite-based composites from industrial side streams. J Clean Prod 211:1065-1077. https://doi.org/10.1016/j. jclepro.2018.11.241

35. Kumar DS, Sah R, Sekhar VR, Vishwanath SC (2017) Development and use of mill scale briquettes in BOF. Ironmak Steelmak 44:134-139. https://doi.org/10.1080/03019233.2016.1165499

36. El-Hussiny NA, Shalabi MEH (2011) A self-reduced intermediate product from iron and steel plants waste materials using a briquetting process. Powder Technol 205:217-223

37. Singh M (2001) Studies on the cold bonded briquettes of iron and steel plant by-products as burden material for blast furnaces. DIVA

38. Singh M, Bjorkman B (2006) Strength of cement-bonded briquettes. Miner Metall Process 23:203-213

39. Elkem Elkem Materials Mixture Analyser software

40. Myhre B, Hundere AM (1996) The use of particle size distribution in development of refractory castables

41. Sarkar R (2016) Particle size distribution for refractory castables: a review. Interceram Int Ceram Rev 65:82-86. https://doi.org/10. 1007/BF03401156

42. British Standards Institution (2015) Iron ore pellets for blast furnace and direct reduction feedstocks - Determination of the crushing strength (BS ISO 4700:2015). British Standards Institution (BSI), London

43. Andersson A, Ahmed H, Rosenkranz J et al (2017) Characterization and upgrading of a low zinc-containing and fine blast furnace sludge: a multi-objective analysis. ISIJ Int 57:262-271. https://doi.org/10.2355/isijinternational.ISIJINT-2016-512

44. Abdelrahim A, Iljana M, Omran M et al (2020) Influence of $\mathrm{H}_{2}-\mathrm{H}_{2} \mathrm{O}$ content on the reduction of acid iron ore pellets in a $\mathrm{CO}-\mathrm{CO}_{2}-\mathrm{N}_{2}$ reducing atmosphere. ISIJ Int. https://doi.org/10. 2355/isijinternational.ISIJINT-2019-734

45. Taylor HFW (1997) Cement chemistry, 2nd edn. T. Telford, London

46. Chang J, Zhang Y, Shang X et al (2017) Effects of amorphous AH 3 phase on mechanical properties and hydration process of C 4 A $3 \mathrm{~S}^{-}-\mathrm{C} \mathrm{S}^{-} \mathrm{H} 2$-CH-H $2 \mathrm{O}$ system. Constr Build Mater 133:314-322. https://doi.org/10.1016/j.conbuildmat.2016.11. 111

47. Adesanya E, Sreenivasan H, Kantola AM et al (2018) Ladle slag cement: characterization of hydration and conversion. Constr Build Mater 193:128-134. https://doi.org/10.1016/j.conbuildmat. 2018.10.179

48. Liu S, Han W, Li Q (2017) Hydration properties of ground granulated blast-furnace slag (GGBS) under different hydration environments. Mater Sci 23:70-77. https://doi.org/10.5755/j01.ms. 23.1.14934

49. Song F, Yu Z, Yang F et al (2015) Microstructure of amorphous aluminum hydroxide in belite-calcium sulfoaluminate cement. Cem Concr Res 71:1-6. https://doi.org/10.1016/j.cemconres.2015. 01.013

50. Edmonds RN, Majumdar AJ (1988) The hydration of $12 \mathrm{CaO}_{7} \mathrm{AI}_{2} \mathrm{O}_{3}$, at different temperatures. Cem Concr Res 18:6

51. Majumbar A, Singh B, Edmonds R (1989) Hydration of mixtures of C12A7 and granulated blastfurnace slag. Cem Concr Res 19:9

52. Aye T, Oguchi CT, Takaya Y (2010) Evaluation of sulfate resistance of Portland and high alumina cement mortars using hardness test. Constr Build Mater 24:1020-1026. https://doi.org/10.1016/j. conbuildmat.2009.11.016

53. Franus W, Panek R, Wdowin M (2015) SEM investigation of microstructures in hydration products of Portland cement. In: Polychroniadis EK, Oral AY, Ozer M (eds) 2nd international multidisciplinary microscopy and microanalysis congress. Springer International Publishing, Cham, pp 105-112

54. Bagatini MC, Zymla V, Osório E, Vilela ACF (2017) Scale recycling through self-reducing briquettes to use in EAF. ISIJ 
Int 57:2081-2090. https://doi.org/10.2355/isijinternational.ISIJI NT-2017-242

55. Sha W, Pereira GB (2001) Differential scanning calorimetry study of hydrated ground granulated blast-furnace slag. Cem Concr Res 31:327-329. https://doi.org/10.1016/S0008-8846(00)00472-5

56. El-Didamony H (1980) Application of differential thermogravimetry to the hydration of expansive cement pastes. Thermochim Acta 35:201-209. https://doi.org/10.1016/0040-6031(80)87194-2

57. Morandeau A, Thiéry M, Dangla P (2014) Investigation of the carbonation mechanism of $\mathrm{CH}$ and $\mathrm{C}-\mathrm{S}-\mathrm{H}$ in terms of kinetics, microstructure changes and moisture properties. Cem Concr Res 56:153-170. https://doi.org/10.1016/j.cemconres.2013.11.015

58. Fang Y, Chang J (2015) Microstructure changes of waste hydrated cement paste induced by accelerated carbonation. Constr Build Mater 76:360-365. https://doi.org/10.1016/j.conbuildmat.2014. 12.017

59. Ahmed HM, Viswanathan NN, Björkman B (2017) Isothermal reduction kinetics of self-reducing mixtures. Ironmak Steelmak 44:66-75. https://doi.org/10.1080/03019233.2016.1165497

60. Sharma T (1993) Non-coking coal quality and composite prereduced pellets. Int J Miner Process 39:299-311. https://doi.org/ 10.1016/0301-7516(93)90022-3
61. Zuo H, Hu Z, Zhang J et al (2013) Direct reduction of iron ore by biomass char. Int J Miner Metall Mater 20:514-521. https://doi. org/10.1007/s12613-013-0759-7

62. Mikhail SA, Turcotte A-M (1998) Thermal reduction of steelmaking secondary materials I. Basic-oxygen-furnace dust. Thermochim Acta 7:9

63. Lotfian S, Ahmed H, El-Geassy A-HA, Samuelsson C (2017) Alternative reducing agents in metallurgical processes: gasification of shredder residue material. J Sustain Metall 3:336-349. https://doi.org/10.1007/s40831-016-0096-y

64. Singh M, Björkman B (2004) Swelling behaviour of cementbonded Briquettes-proposed Model. ISIJ Int 44:482-491. https:// doi.org/10.2355/isijinternational.44.482

Publisher's Note Springer Nature remains neutral with regard to jurisdictional claims in published maps and institutional affiliations. 